\title{
أسلوب التعجب في القرآن الكريم
}

$$
\text { جمال رباح }
$$

أستاذ مساعد- جاهعة القدس المفتوحة- فلسطين jnibraheem@qou.edu 


$$
\text { المجلة الدولية للدراسـات اللغوية والأدبية العربية }
$$

International Journal for Arabic Linguistics and Literature Studies (JALLS)

\section{$\underline{\text { www.refaad.com }}$}

\title{
أسلوب التعجب في القرآن الكريم
}

\author{
جمال رباح \\ أستاذ مساعد- جامعة القدس المفتوحة- فلسطين \\ jnibraheem@qou.edu
}

DOI: https://doi.org/10.31559/JALLS2021.3.2.4 2021/7/10 2021/5/29 مراجعة البحث: 2021/6/28 قبول البحث البحث: 2010

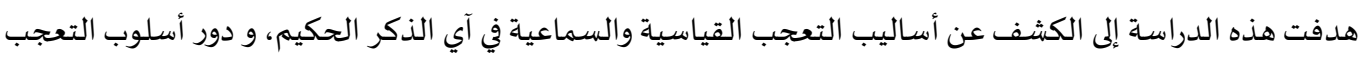

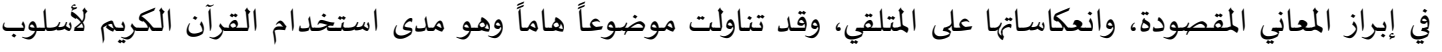

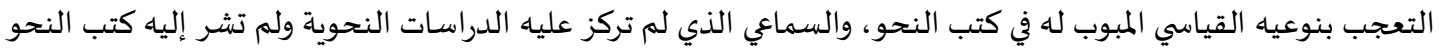
إلا بإشارات خجولة.

وقد أظهرت الدراسة أن أكثر الاستخدامات، وبعد تتبعها في القرآن الكريم، كانت للأساليب السماعية بكل صيغها، التهائ

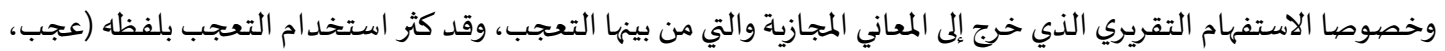

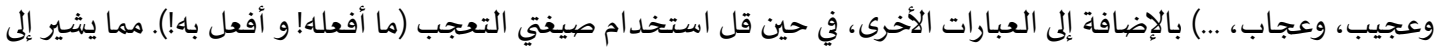

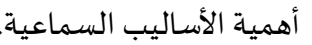

وقد جاء هذا البحث في مبحثين ومقدمة وتمهيد وخاتمة، تناول المبحث الأول مفهوم التعجب لغة واصطاحلاحاً، وأساليب

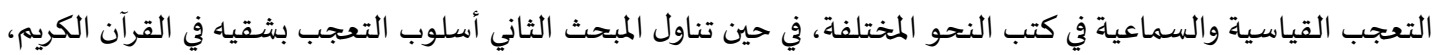

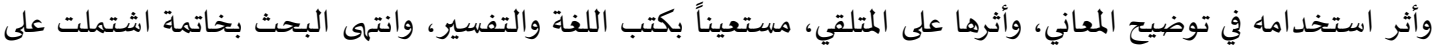

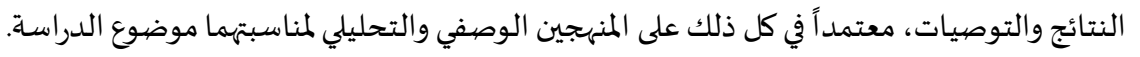
الكلمات المفتاحية: التعجب القياسي؛ التعجب السماعي؛ القرآن الكريم.

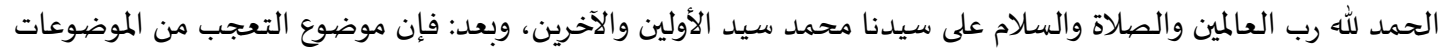

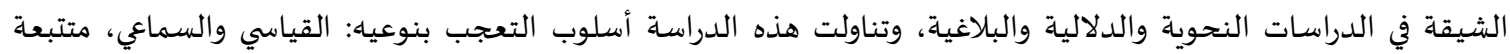

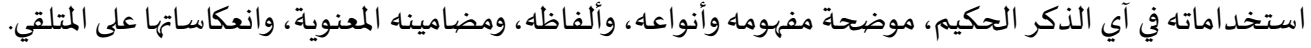

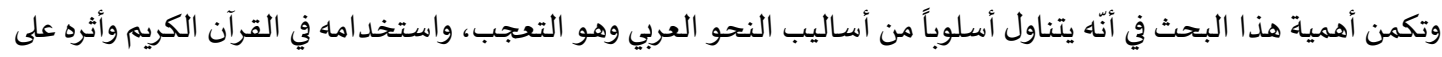

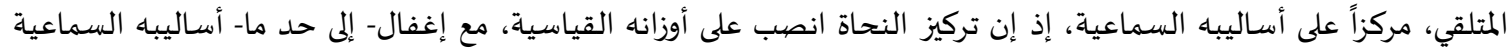
المستخدمة أكثر بكثير من أساليبه القياسية. ويهدف هذا البحث إلى الكثف عن أساليب التعجب القياسيّة والسماعيّة في آي الذكر الحكيم، وألفاظه وأساليبه المتنوعة وأثرها في إظهار المعنى المقصود وذانعكاس المثاته على القارئ والمتلقي. 
وقد اهتم البحث باستقراء أساليب التعجب في القرآن الكريم، ولذلك اعتمد الباحث في ذلك على المنهجين الوصفي والتحليلي

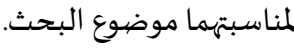

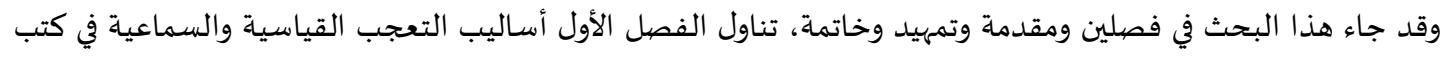

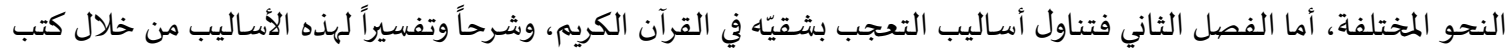

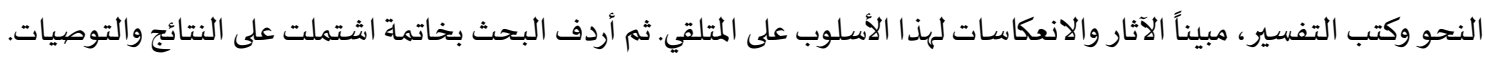

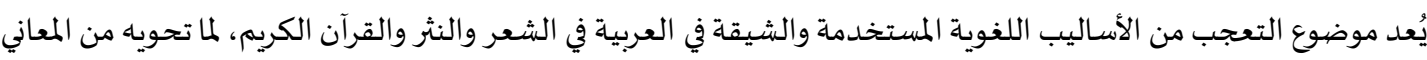

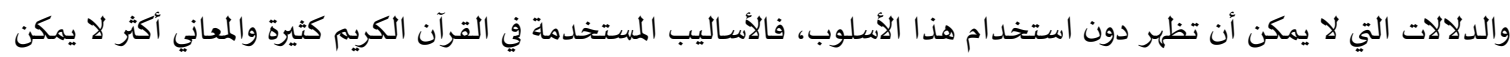

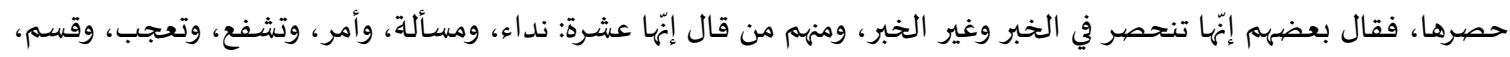

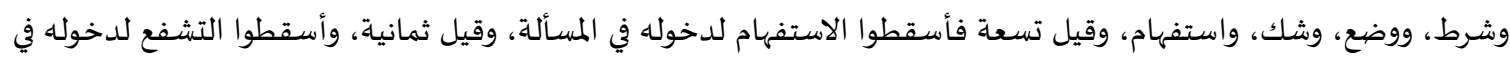

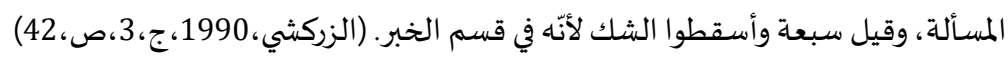

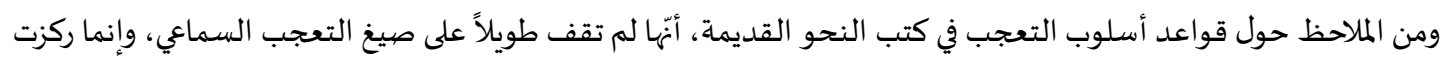

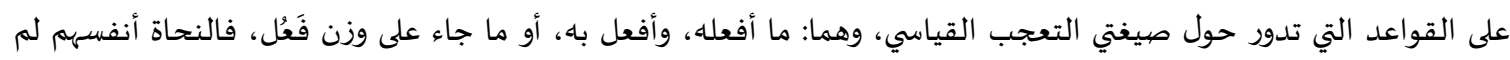

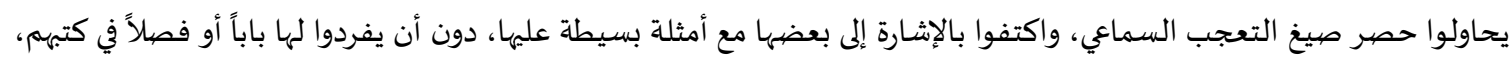

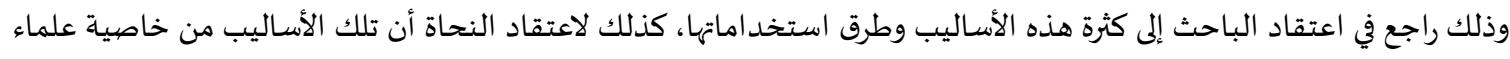

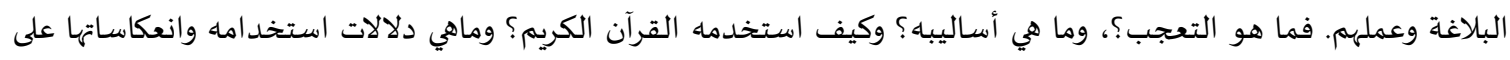

\section{المبحث الأول: أساليب التعجب القياسيّة والسماعيّة.}

المطلب الأول: التعجب لغة واصطلاحاً:

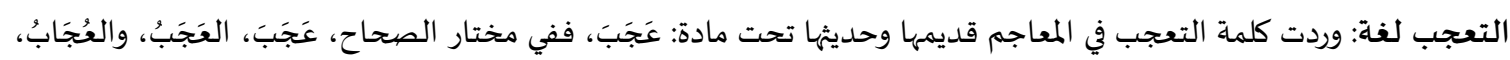

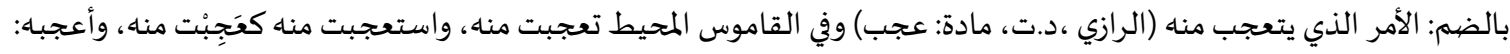

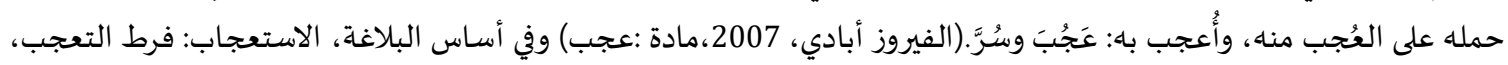

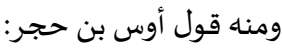

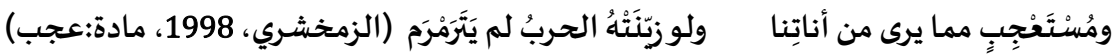

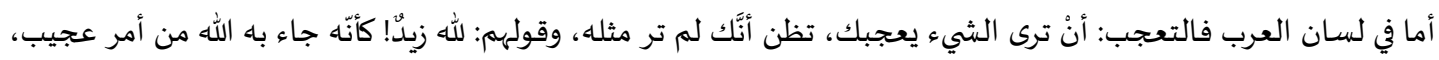

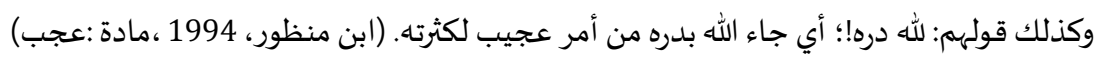

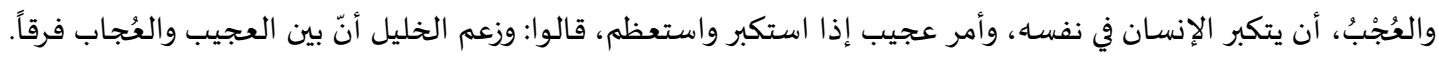

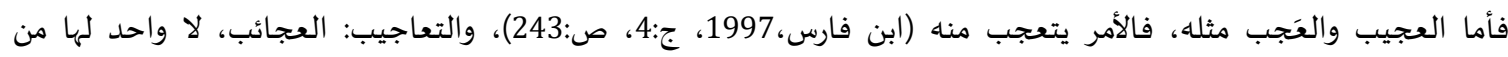

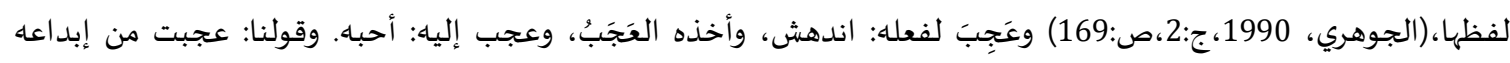

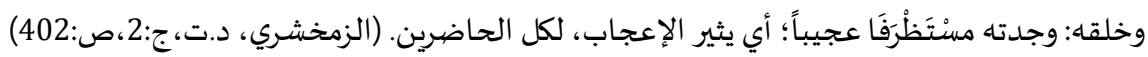

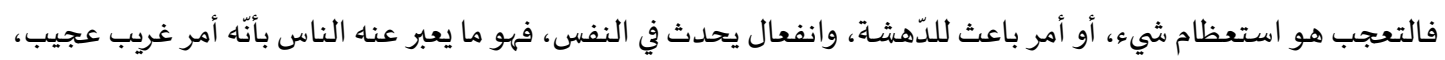
أو أمر مثير.

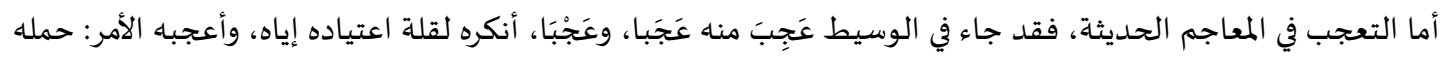

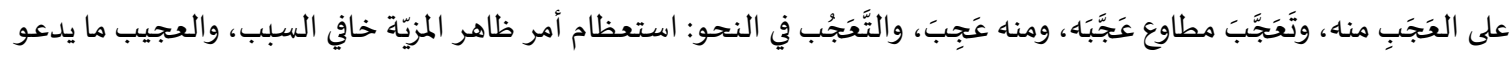

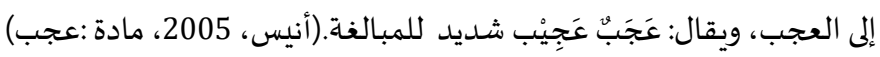

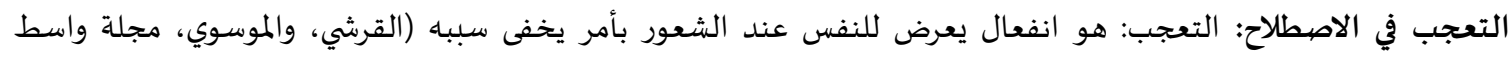

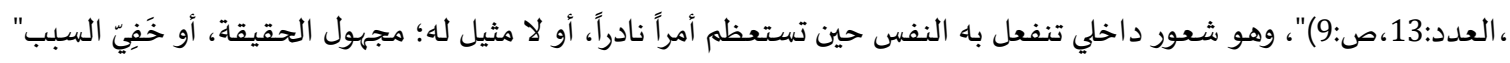

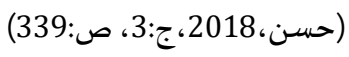


وهو روعة تأخذ الإنسان عند استعظام الثيء، وقد يكون إنكار الأمر لقلة اعتياده إياه، وهو ردة فعل محمودة العواقب إنْ

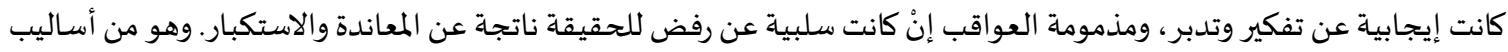

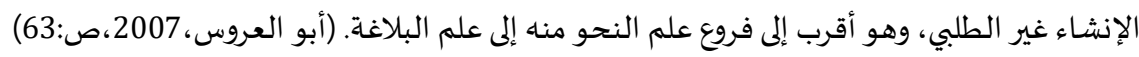
أما ابن عصفور فيرى أنّ " التعجب استعظام في وصف الفروعاع الفاعل خفي سبيها، وخرج بها المتعجب مناه عن نظائره، أو قل نظيره،

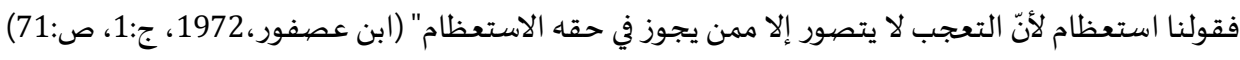

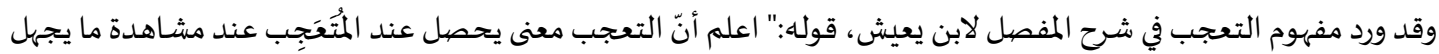

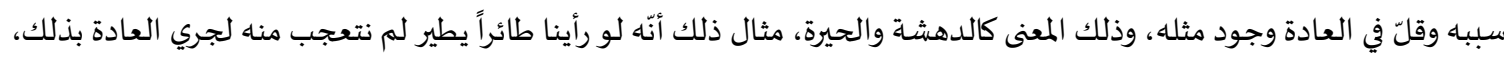

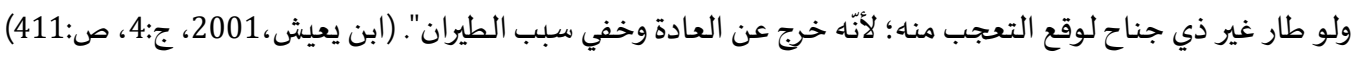

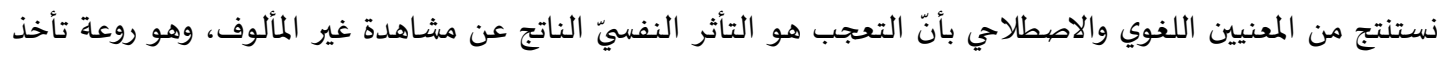

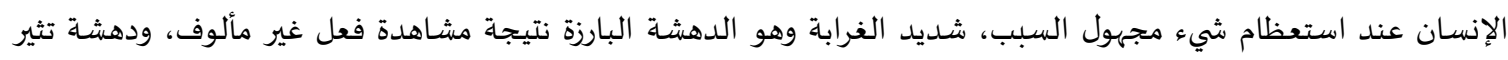

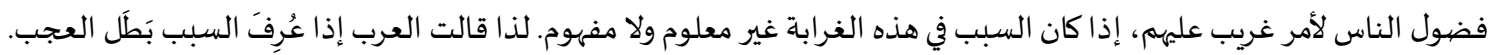

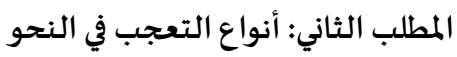

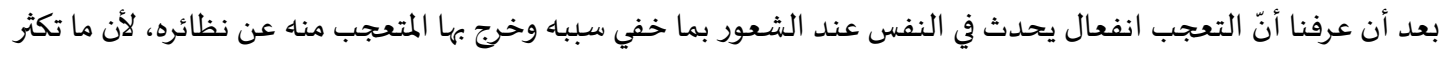

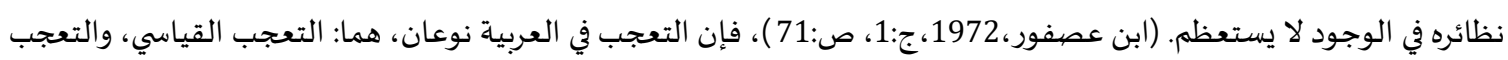
السماعي.

أولاً: التعجب القياسي (الاصطلاحي)

وهو التعجب الذي تناولته كتب النحو القديمة والحديثة والمبوب لله بالتفصيل، ولله صيغتان قياسيتان، ما أفعلها و أفعل بها!

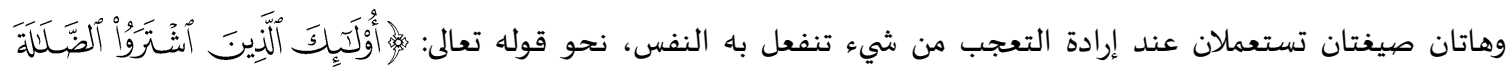

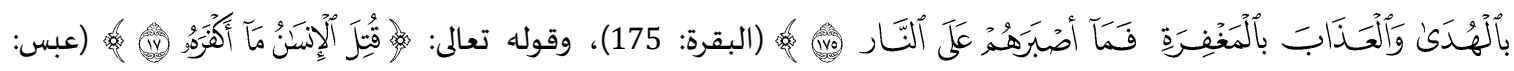

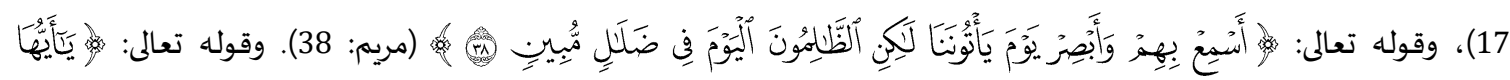

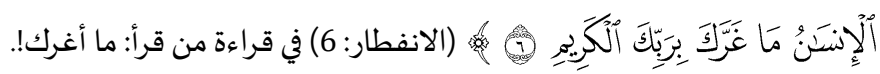

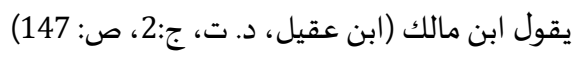

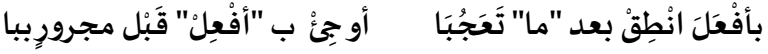

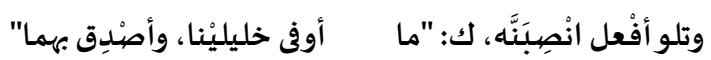

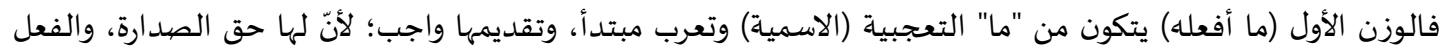

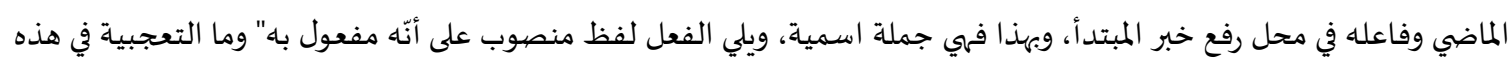

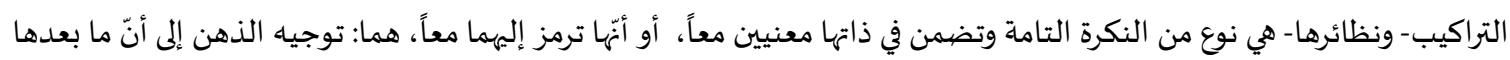

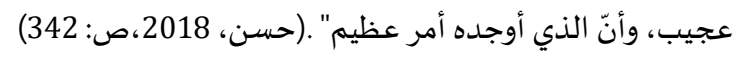
ومنه قول الطغرائي في لامية العجم: أندان

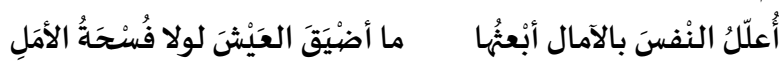

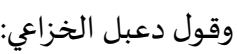

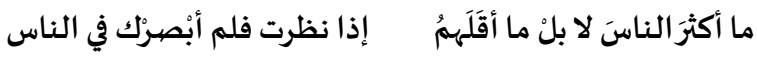
وقول علي بن أبي طالب كرم الله وجها: جزى اللهُ عني، والجزاء بفضله، ربيعةَ خيرا، ما أعَفَّ و أكرما ومنه قول امرئ القيس:

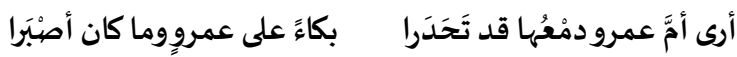

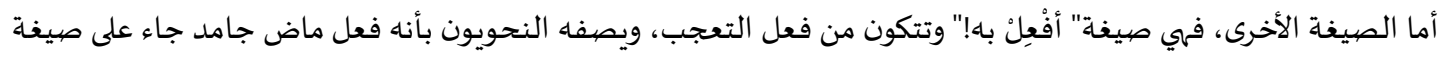

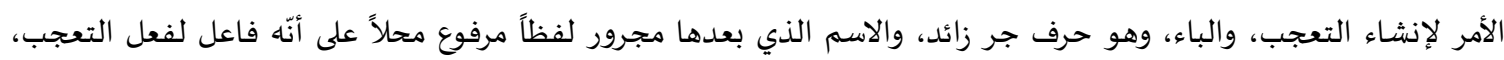


والمتعجب منه، وهو اسم أو ضمير، مجرور لفظاً فقط على أنّه فاعل لفعل التعجب، بوصفه فعلاً ماضياً في التقدير أيضاً. ومنه قوله

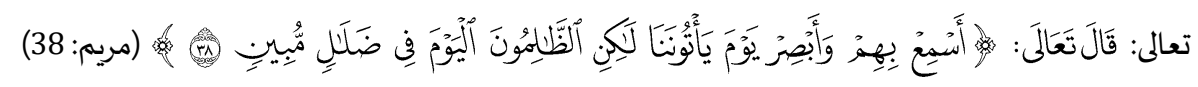

\section{وقال نبيُّ المسلمين تقدموا وأحَبِبْ إلينا أنْ تكون المُقَدَّما}

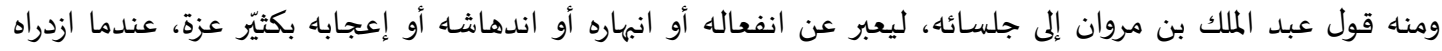

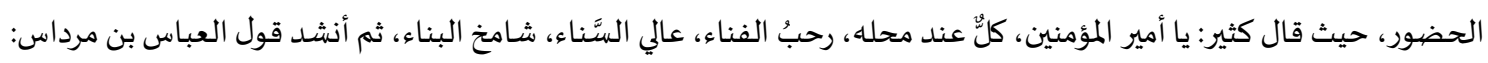

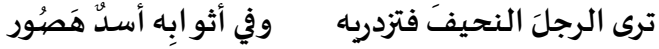

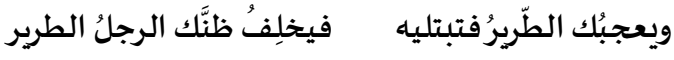

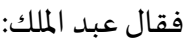

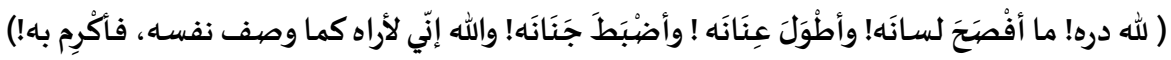

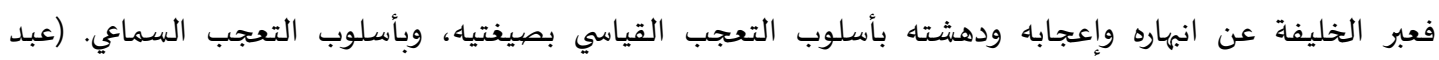

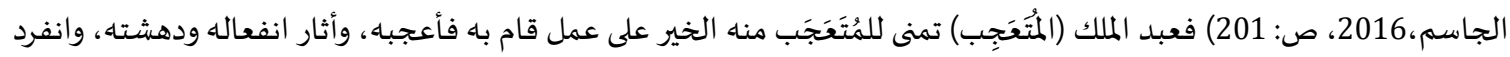

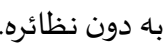

ثانياً: التعجب السماعي:

ويعرف بالتعجب غير المبوب لله في كتب النحو، ويقصد باه تلك الأساليب التي هي أصلاً لغير التعجب، ثم تدل عليه التباه بالاستعمال

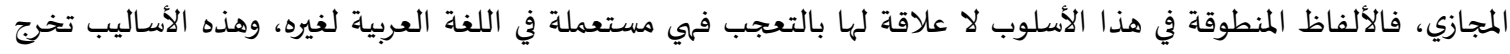

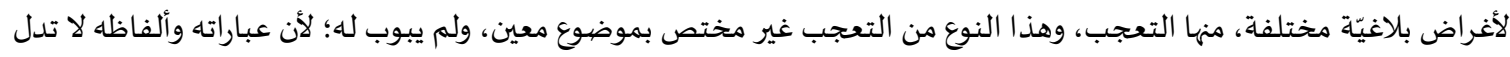

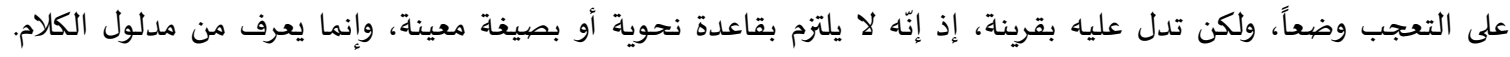

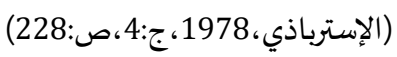
ولهذا فقد قيل وإنما لم يبوب له في النحو لأنها لم تدل بالوضعي، بل بالعربية ولا تفهم إلا بتضافر القرينة وهو أسلوب غير التهري

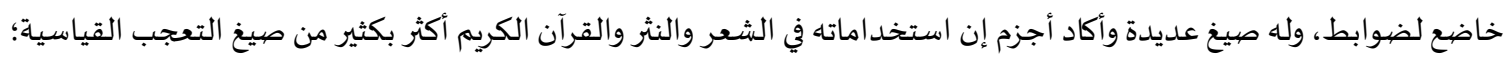

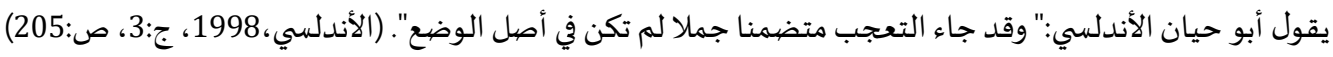

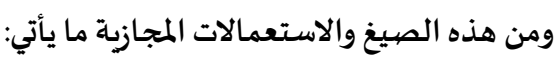

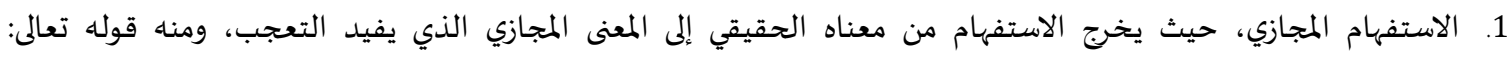

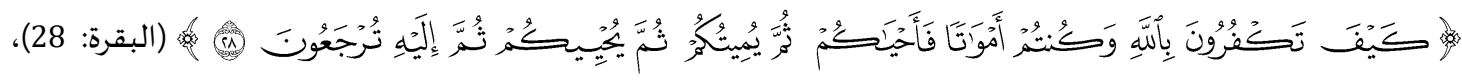

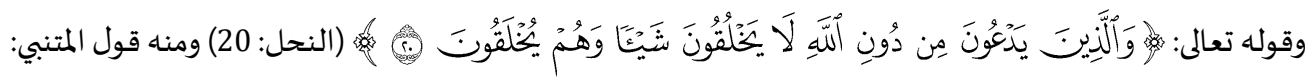

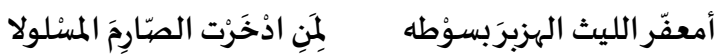

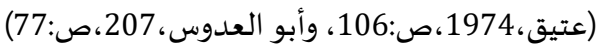

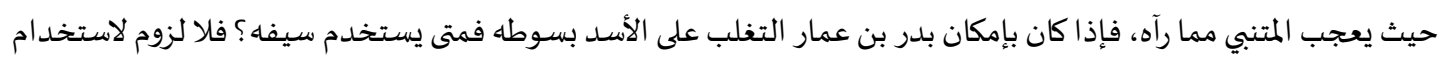
السيف ، ونحو قول المتنبي وقد أصيب بالحمى:

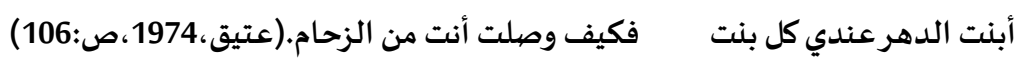

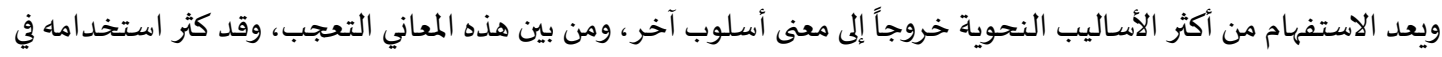
القرآن الكريم، وبمختلف أدواته وألفاظه.

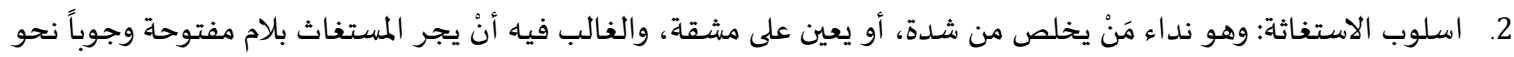

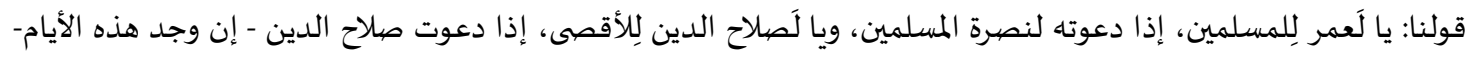

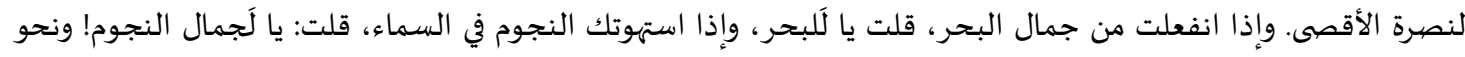

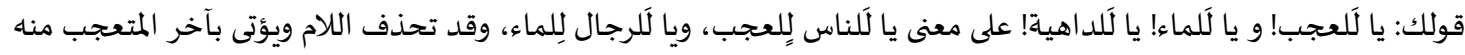

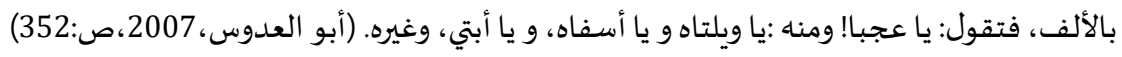
ومناه قول الشاعر إمرئ القيس:

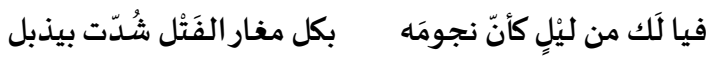




\section{فيا لك بحرا لم أجِدْ فيه مشربا وإنْ كان غيرواجدا فيه مسبحا}

فدلالة التعجب واضحة في البيتين السابقين، باستخدام صيغة التعجب (يا لك)، فالياء حرف نداء وتعجب اجب

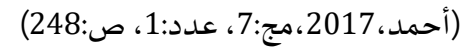

3. المصدر، سبحان الله، يقول ابن فارس: العرب تقول: سبحان مَنْ كذا؛ أي ما أبعدها؛ قال الأعشى:

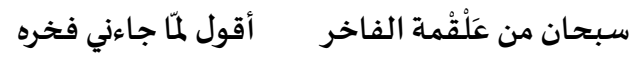

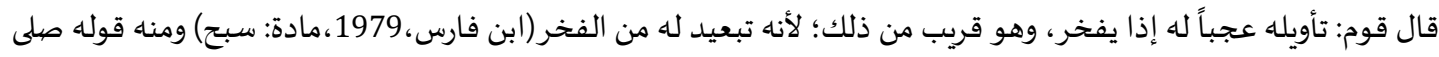

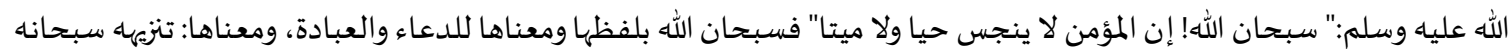

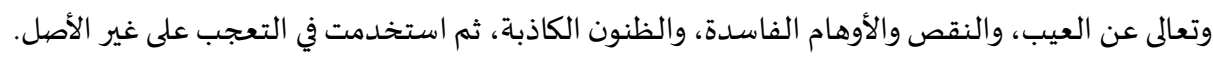

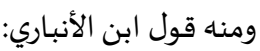

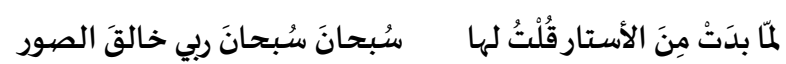

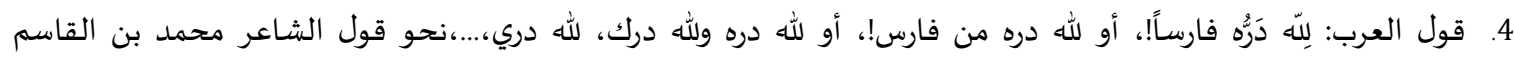
الهاشمي(أبو العيناء) من شعراء العصر العباسي:

لله درّك أيُّ جَنَّة خائفٍٍ ومتاع دنيا أنت للحدثان

\section{فلله دري يوم أَترك طائعا بنيَّ بأعلى الرقمتين وماليا} ومنه قول الشاعر مالك بن الريب:

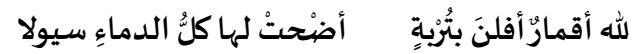

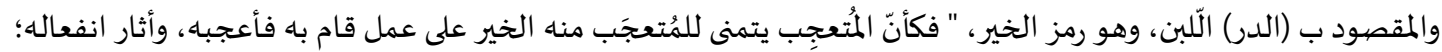

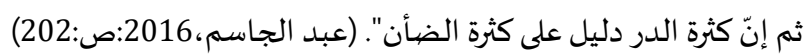

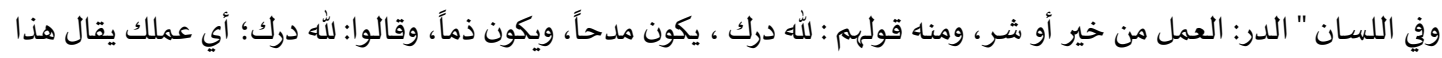

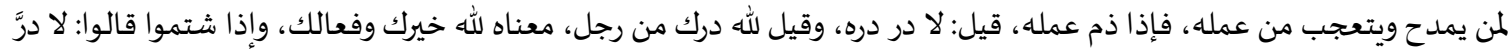

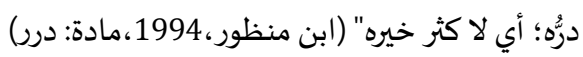

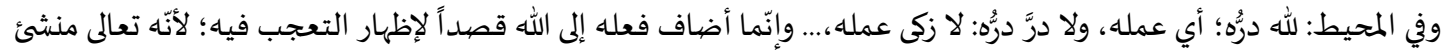

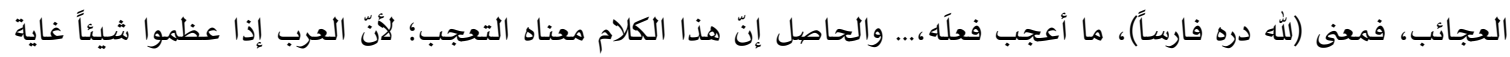

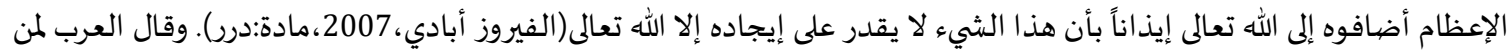

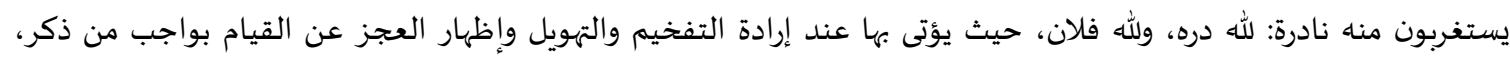

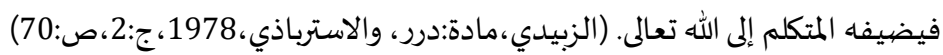

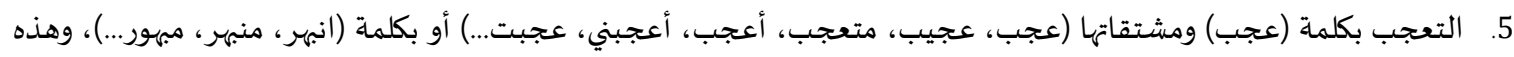

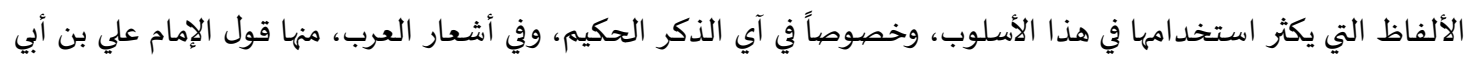

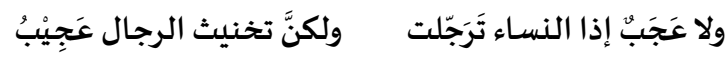

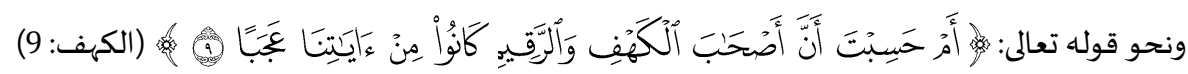

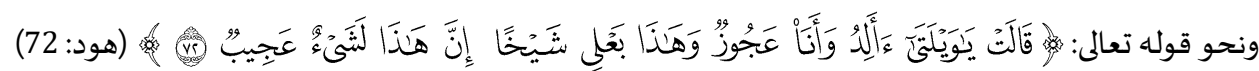

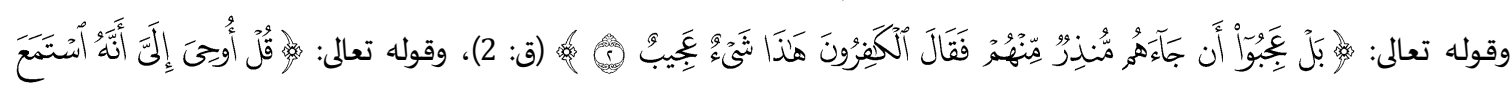

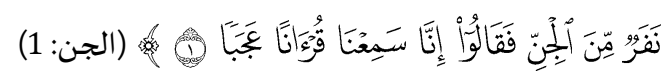

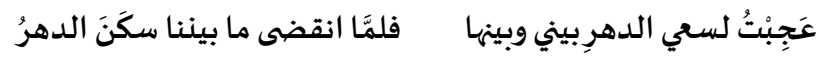

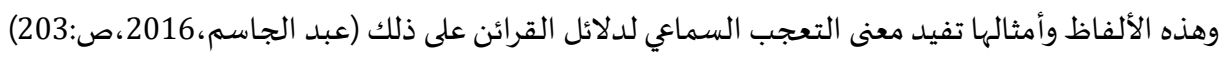


6. التعجب بأسماء الأفعال (حسبك به) بمعنى أكفف، وهي جملة لفظها لفظ الخبر ومعناها معنى الأمر ولمًا كانت تحمل معنى الخبر

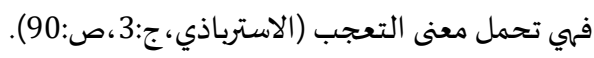

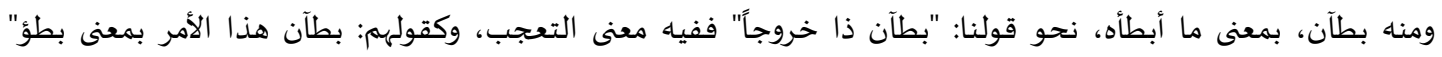

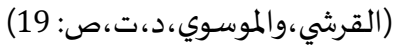

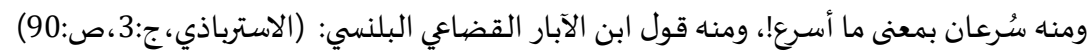

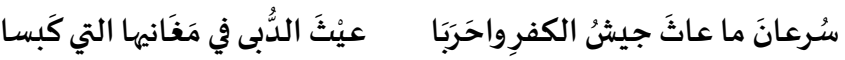

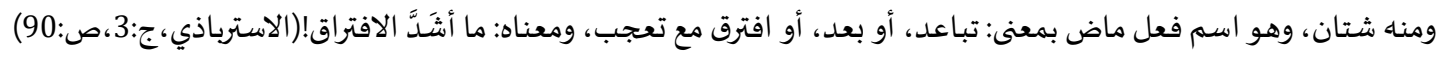

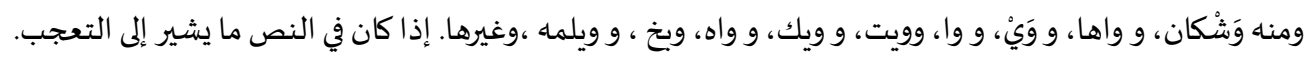

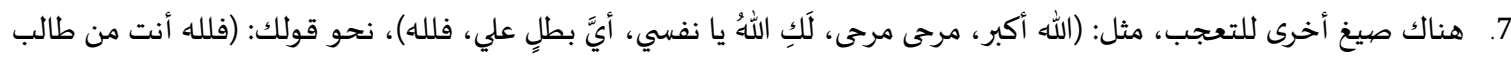

مجد).ونحو قول الشاعر الأعشى:

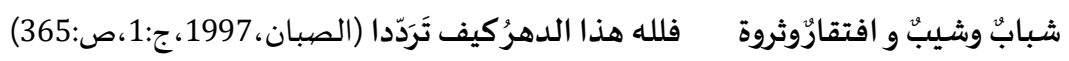

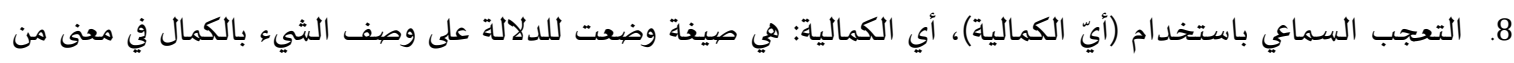

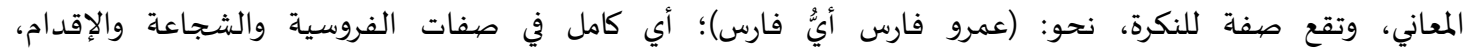

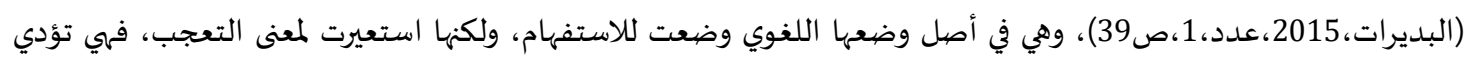

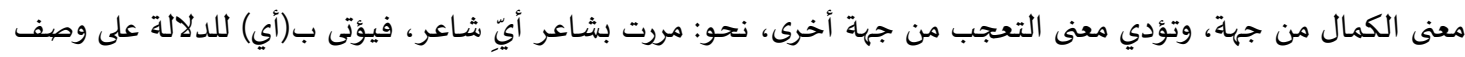

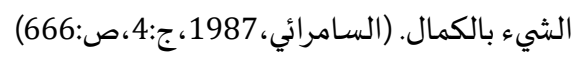

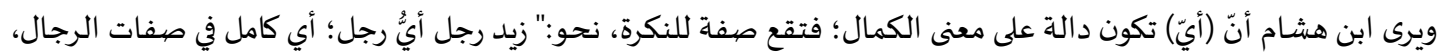

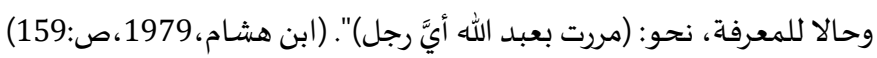

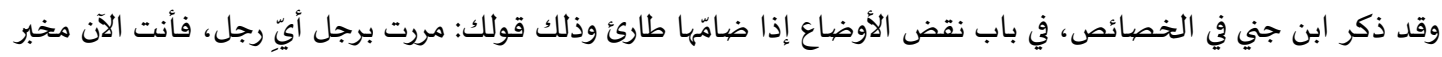

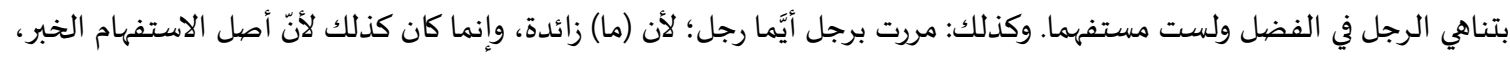

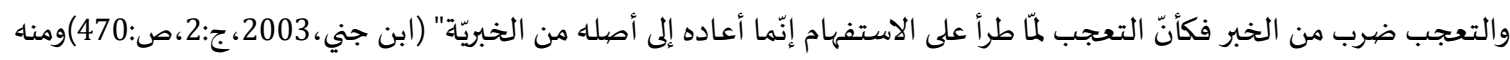

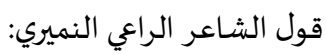

فأومأُتُ إيماءً خفيّا لحبتٍَِّ ولله عينا حبتر أيّما فتى

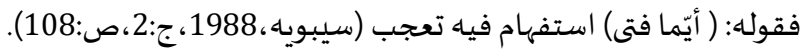

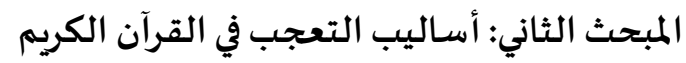

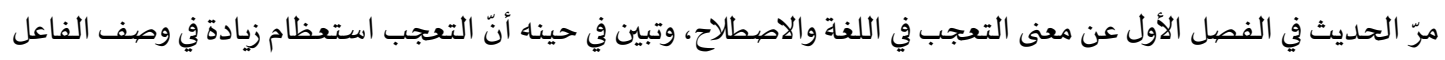

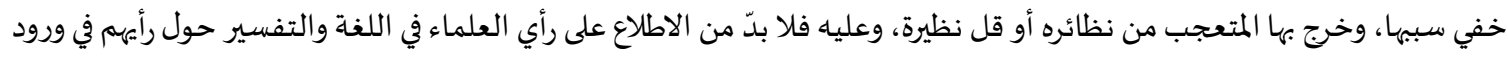
التعجب من الله عز وجل. يرى ابن عصفور أنه" لا يجوز أنْ يرد التعجب من الله لأنّ التعجب لا يتصور إلا ممن يجوز في حقه الاستعظام" (ابن

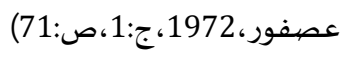
ويرى ابن عادل الحنبلي في كتابه (اللباب في علوم الكتاب) في فصل أسماه (في بيان صفات لا تثبت في حق الله)، منها" الاستهزاء،

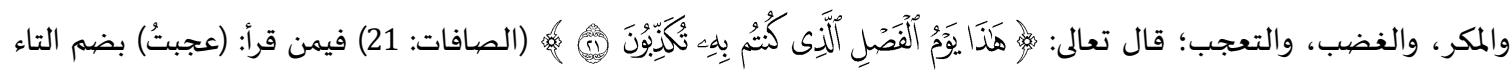

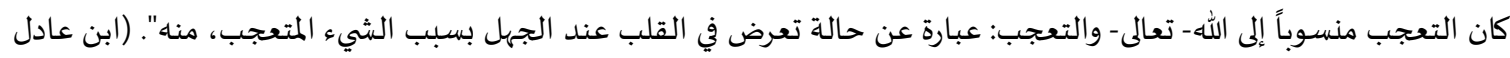

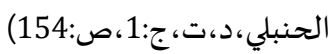

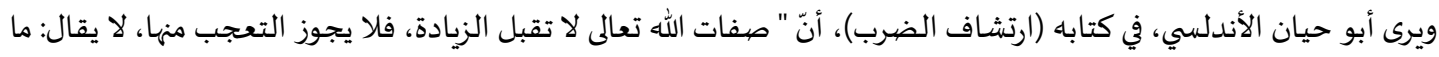

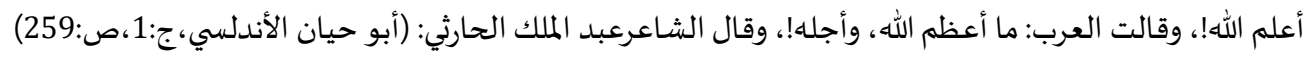

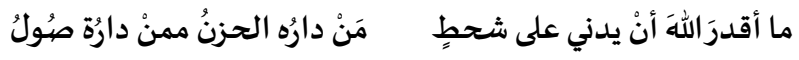




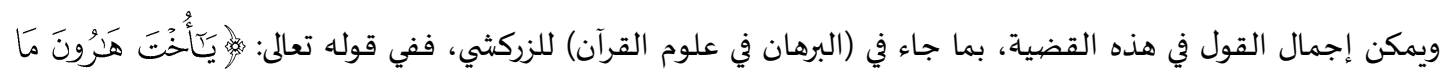

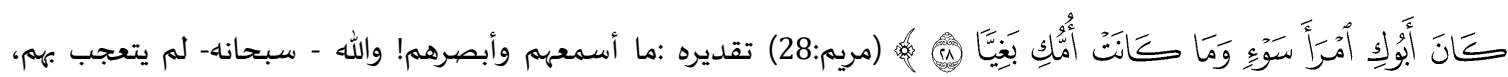

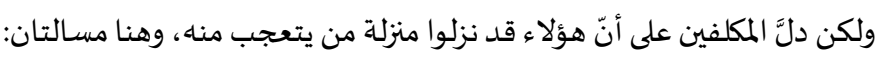

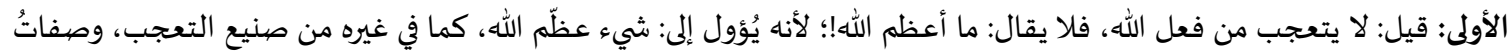

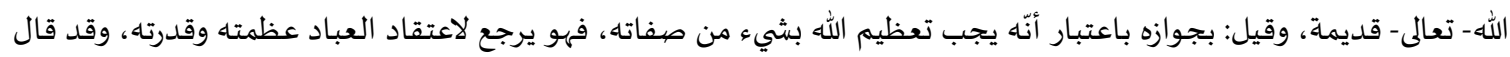

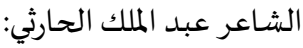

\section{ما أقدرَ اللهَ أنْ يُدني على شَحطٍِ مَنْ دارُه الحزنُ ممن دارُه صهولُ}

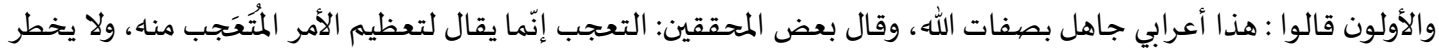

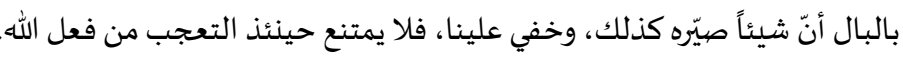
والثانية: هل يجوز إطلاق التعجب في حق الله -تعالى-؟ فقيل: بالمنع؛ لأنّ التعجب استعظام ويصحبه الجهيل والله-سبحانه- منزه عن

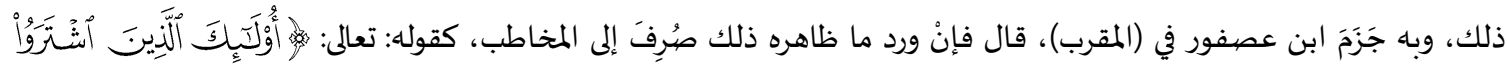

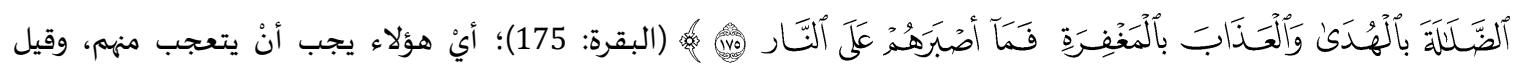

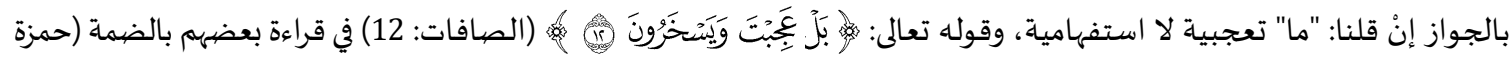

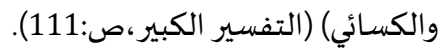

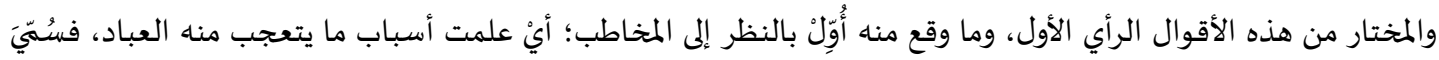

$$
\text { العلمُ بالعجب عجباً. }
$$

وأصل الخلاف في هذه المسالة يلْتفّ على خلاف آخر، وهو أن حقيقة التعجب؛ هل يشترط فيه خفاء سببه فيتحير فيه المتعجب

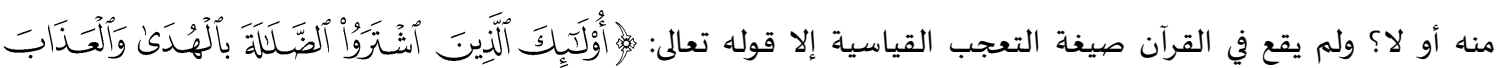

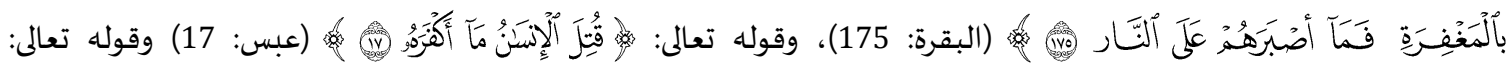

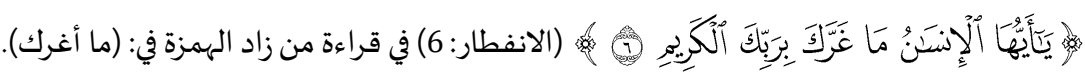

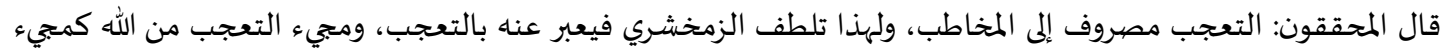

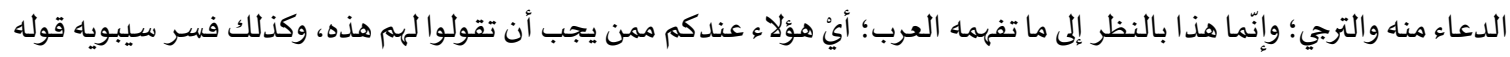

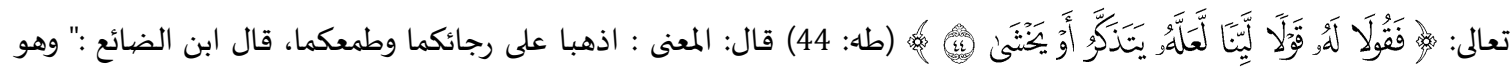

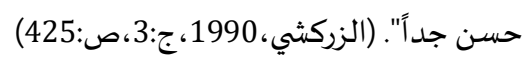

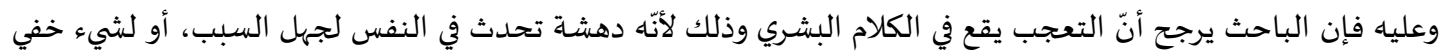

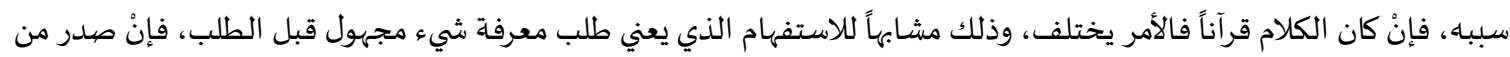

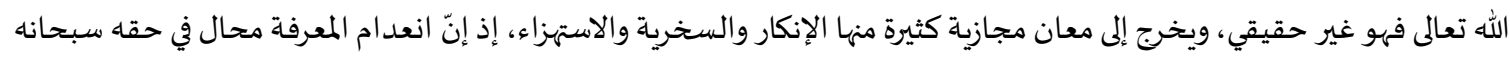

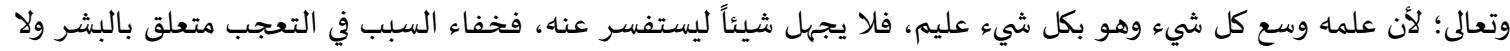

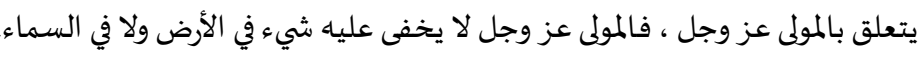

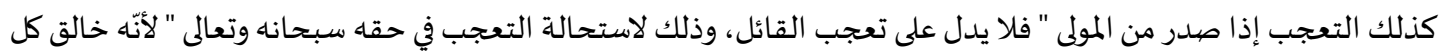

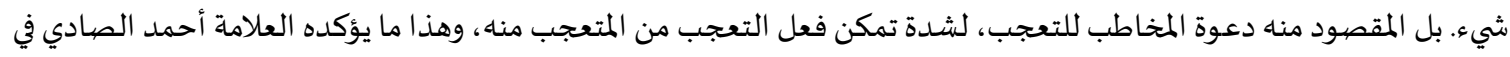

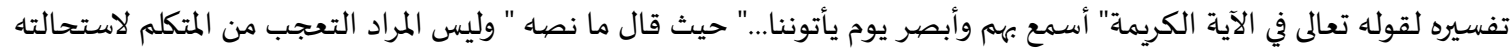

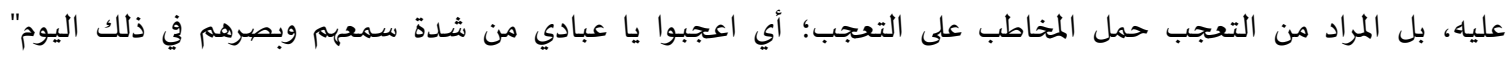
(دلوم،2016،بحث منشور عبر الانترنت)

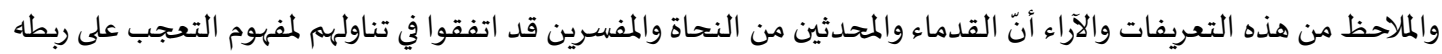

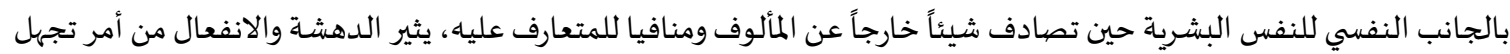
سببه، وحاشا لله أنْ يجهل السبب في أبيّ شيء، والله تعالى أعلى وأعلم. 
وعليه فسيقوم الباحث بتتبع صيغ التعجب بشقيه القياسي والسماعي في آي الذكر الحكيم وتوضيح تلك الصيغ، من كتب التفسير واللغة، معتمداً على ترتيب السور في القرآن الكريم والله المستعان: سورة الفاتحة: خلت من أسلوب التعجب . معند

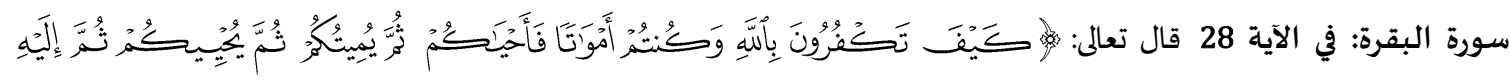

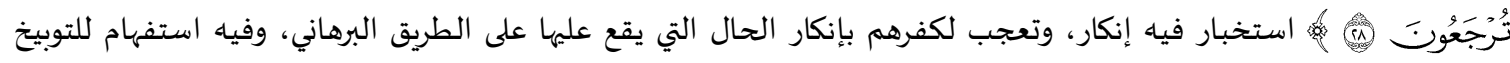

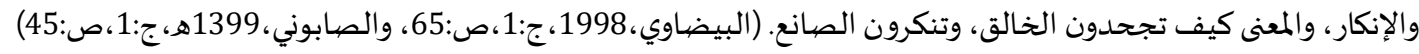

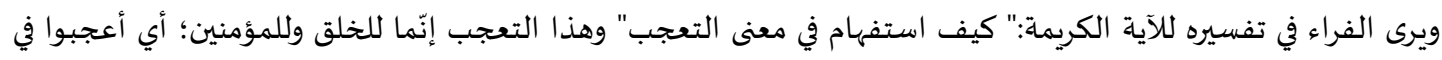

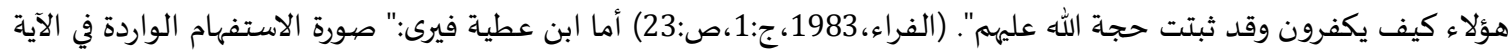

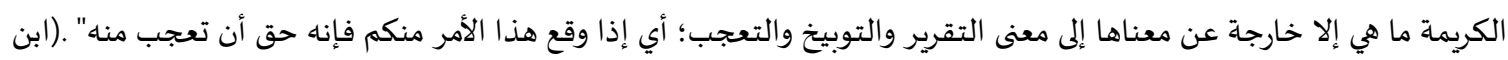

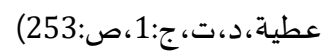

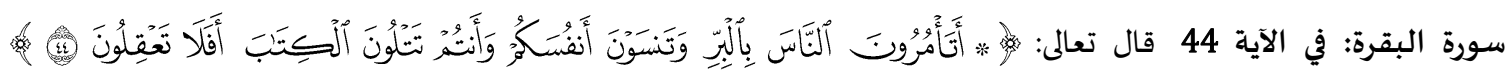

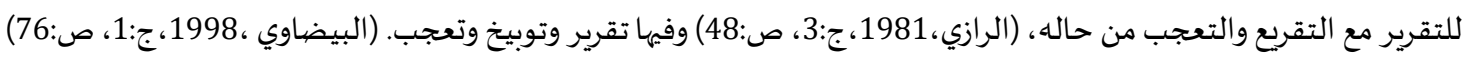

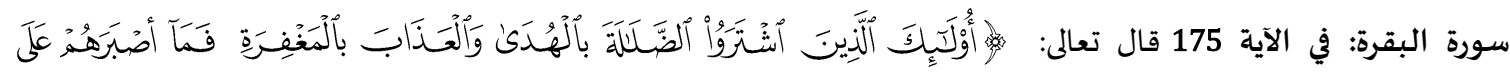

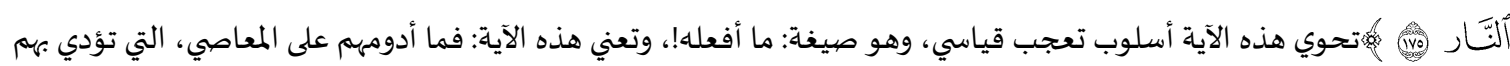

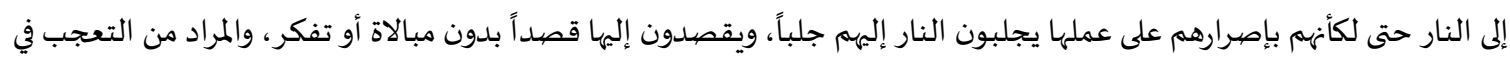

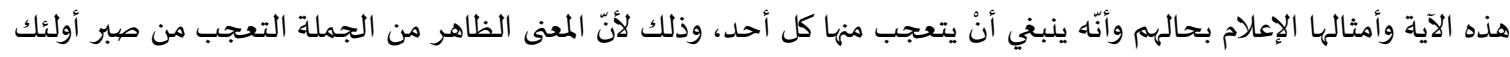

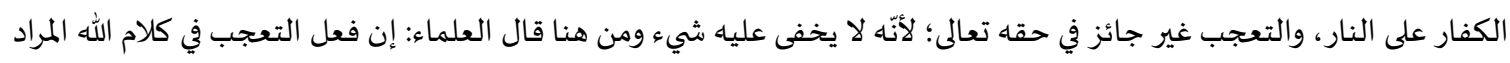

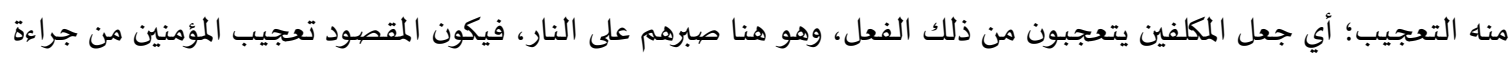

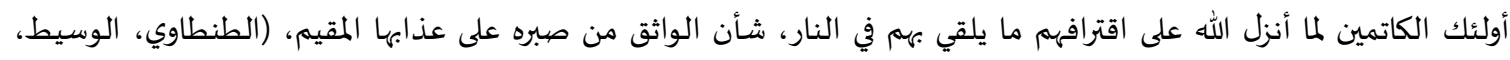

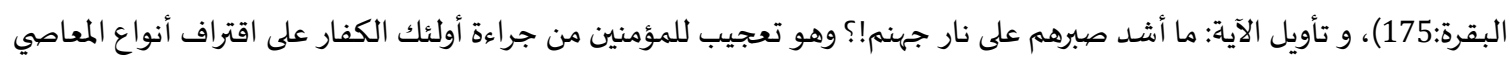

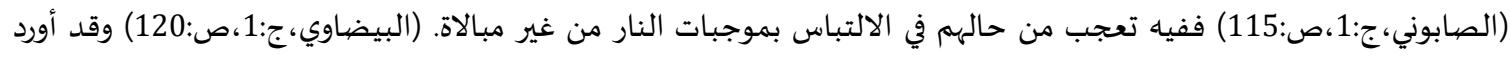

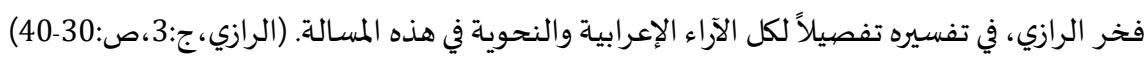

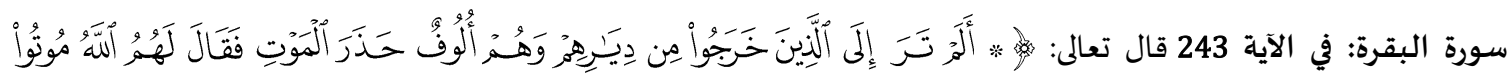

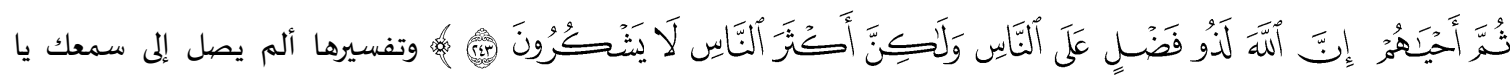

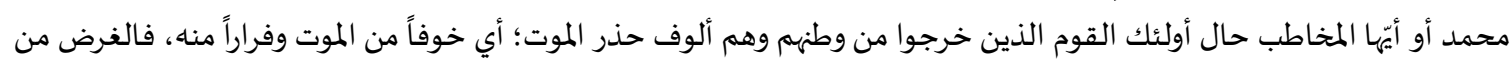

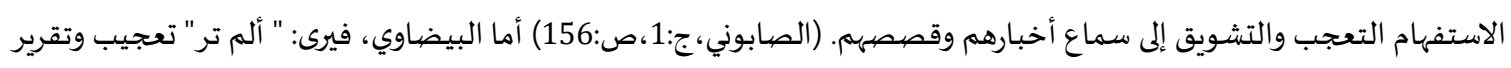

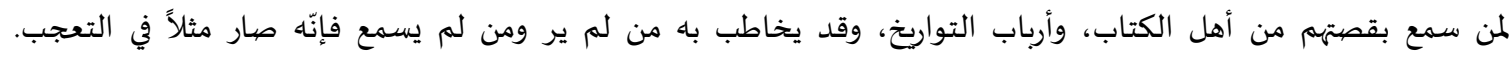

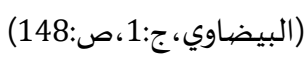

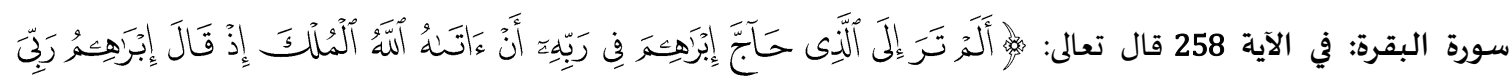

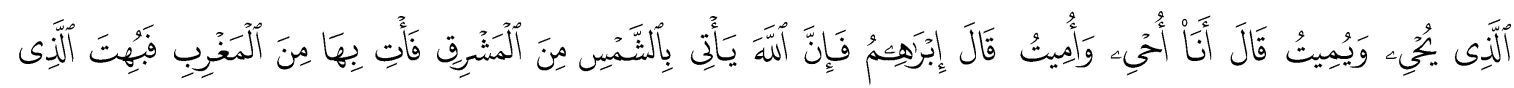

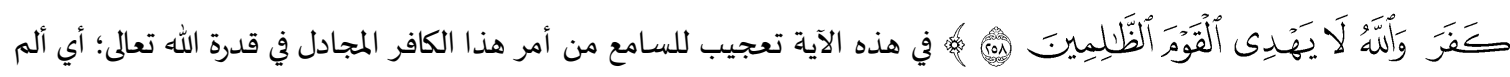

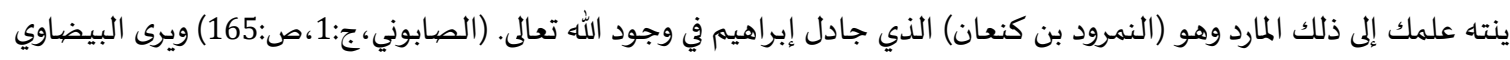

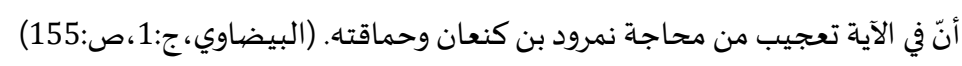

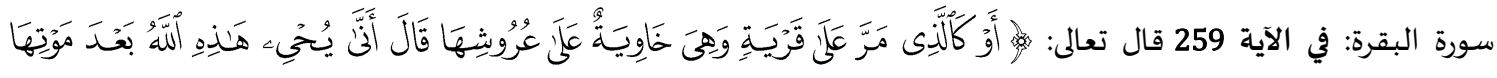

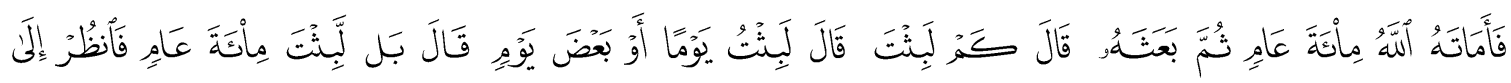

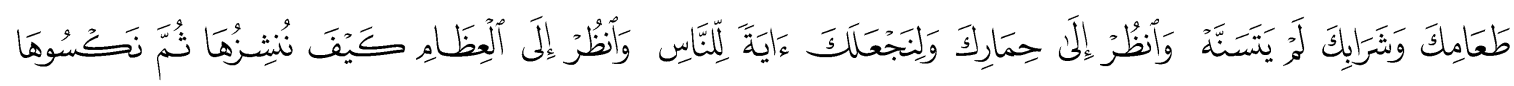




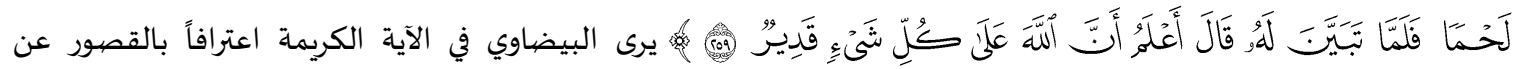

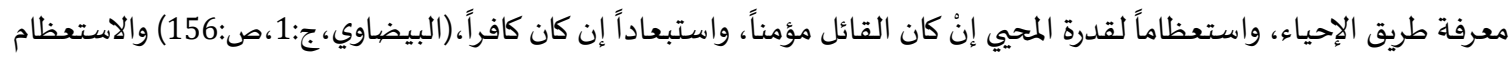

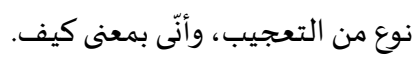
وفي هذه الآية وحسب الرأي الأشهر، قال ذلك الرجل الصالح واسمها(عزيز) كيف يحيي الله هذه البلدة بعد خرابها ودمارها؟ قال

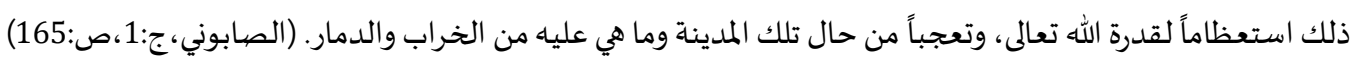
آل عمران: خلت من أساليب التعجب.

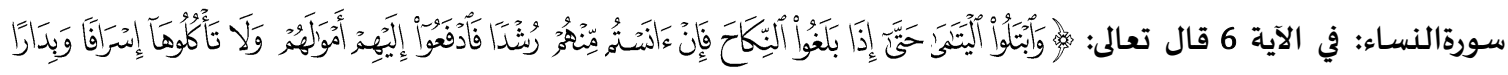

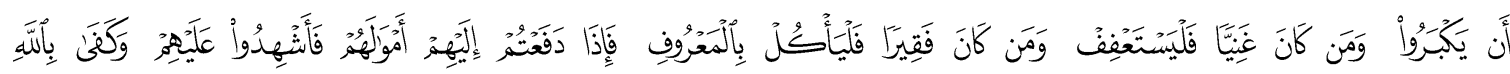

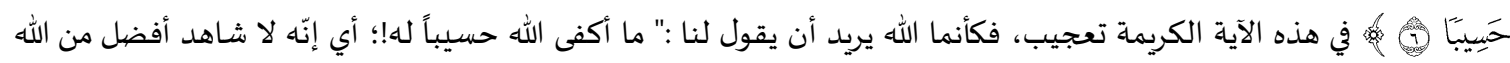

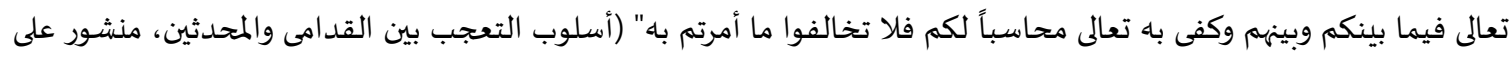
الانترنت).

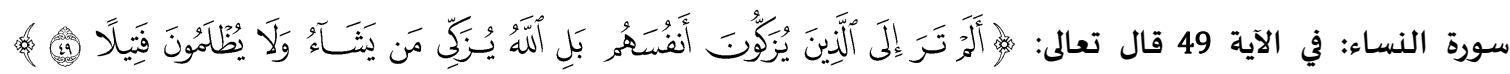

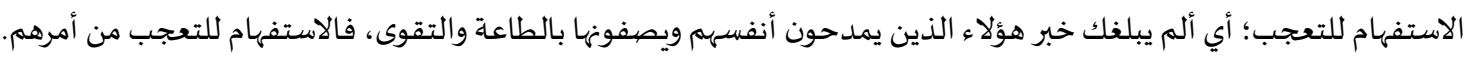

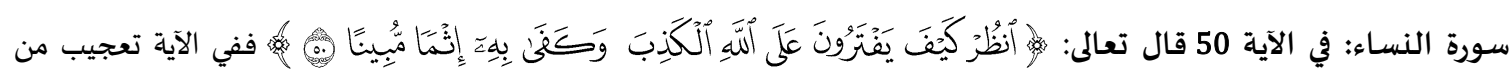
افترائهم وكذبهم .(الصابوني،ج:1،ص:281)

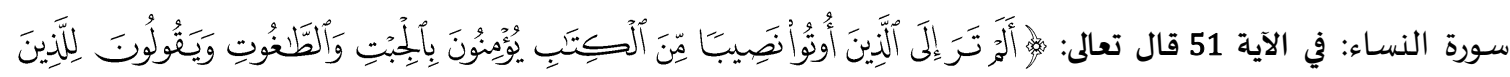

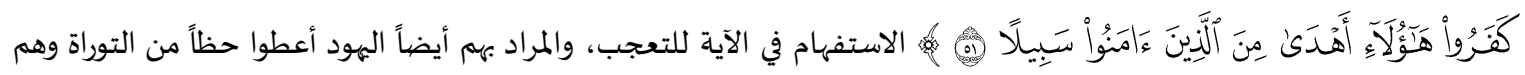

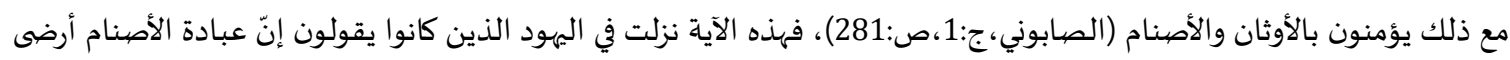

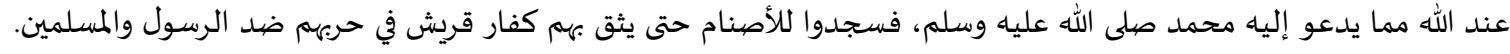
(البيضاوي،ج:1،،ص:78)

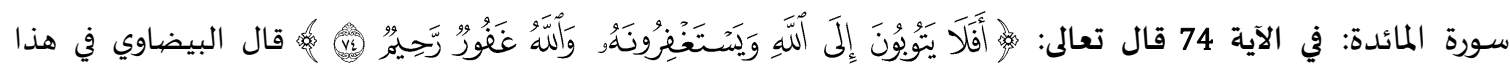

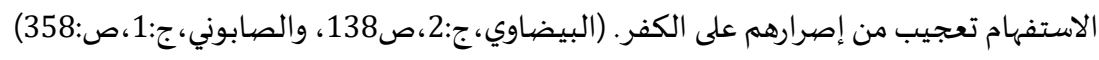

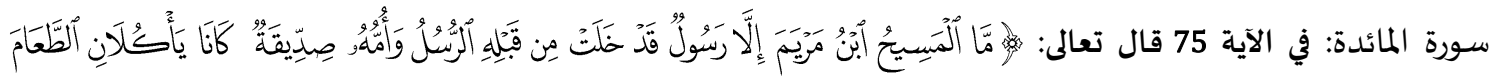

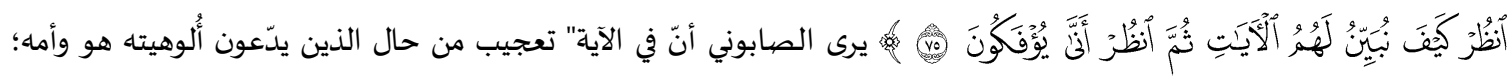

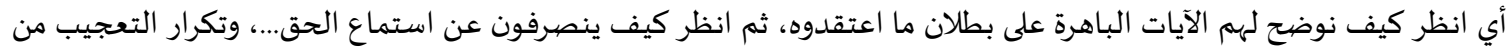

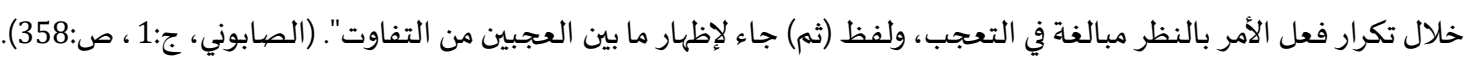

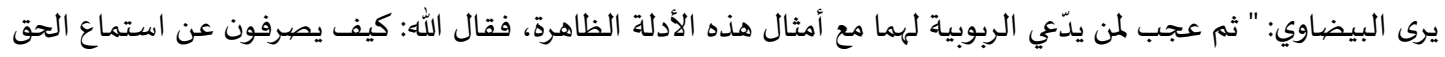

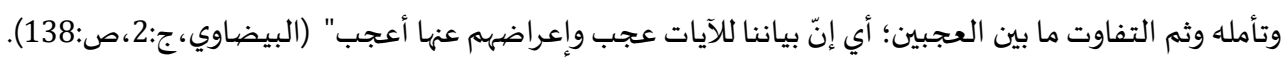

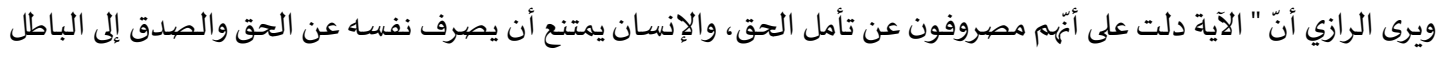

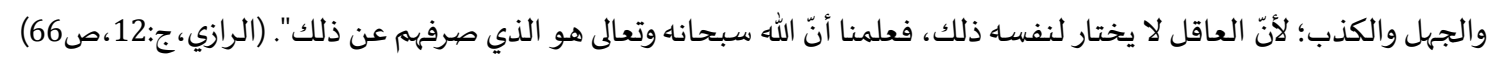

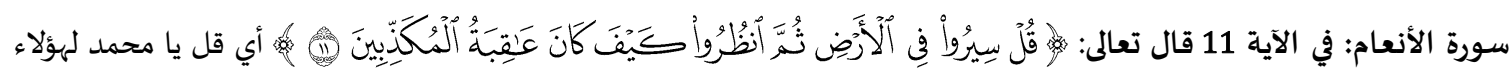

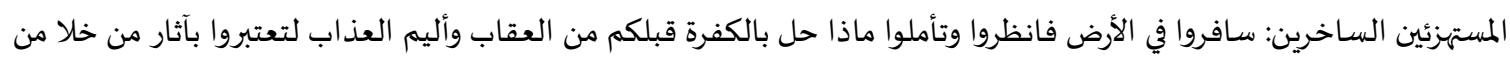

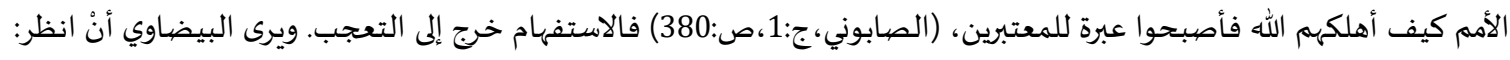

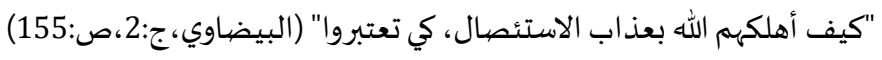




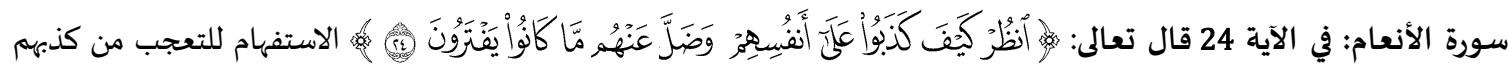

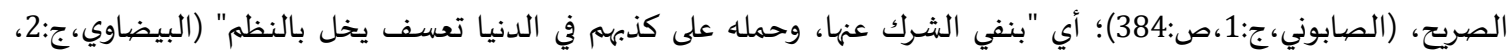

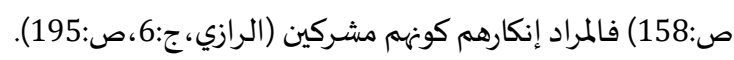

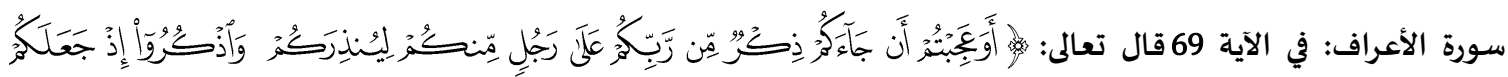

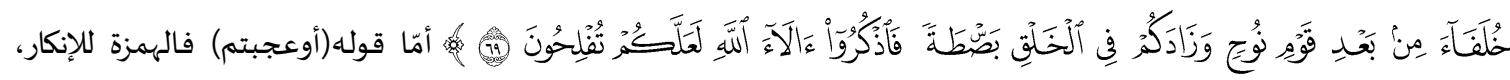
والواو للعطف، والمعطوف عليه محذوف، كأنه قيل: أكذبتم وعجبتم؛ أي عجبتم أنْ جاءكم ذكر" ففي الآية إنكار وتعجب

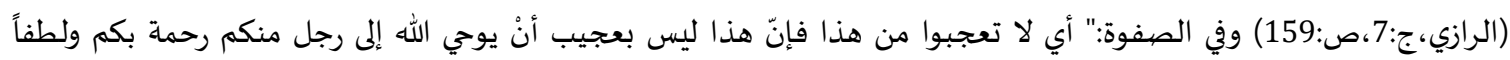

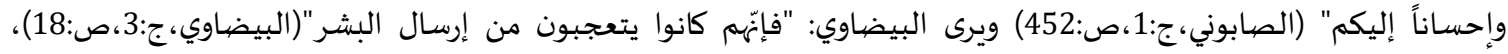

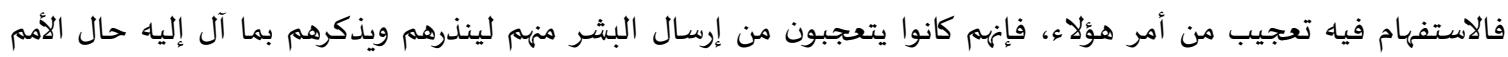

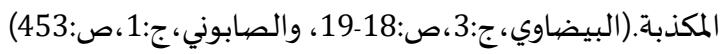

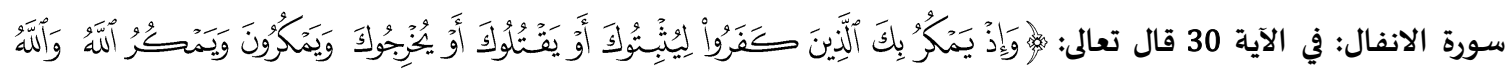

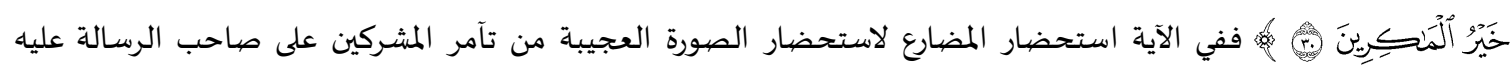

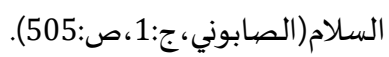
سورة التوبة: خلت سورة التوبة من أسلوب التعجب.

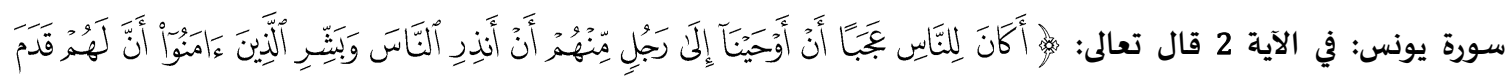

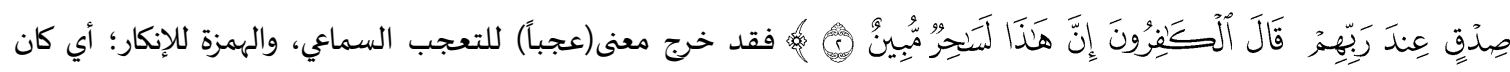

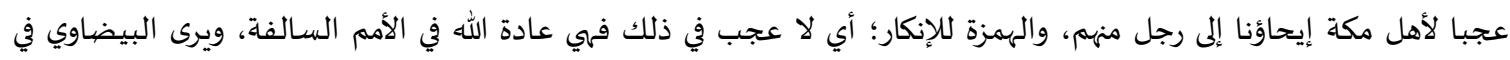

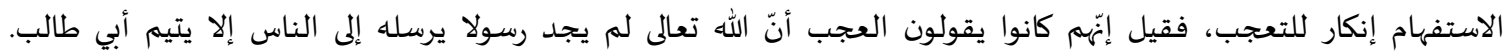

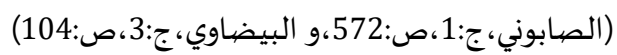

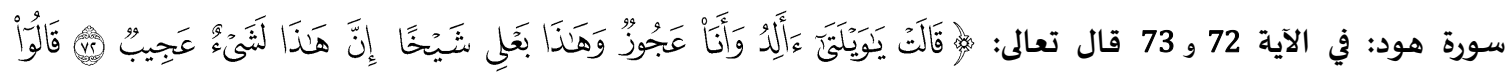

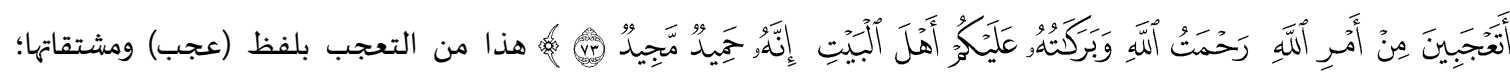

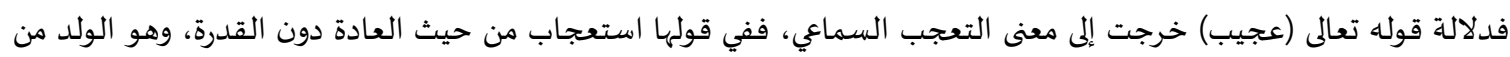

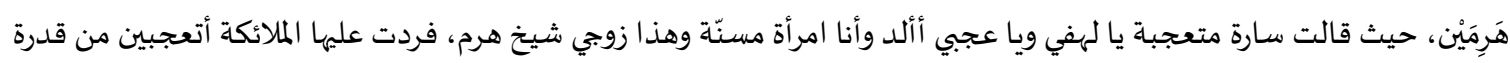

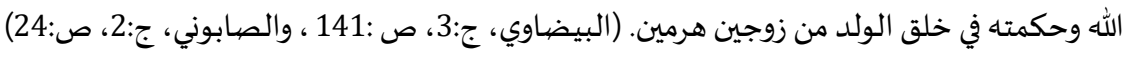

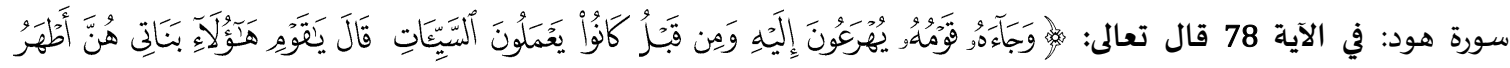

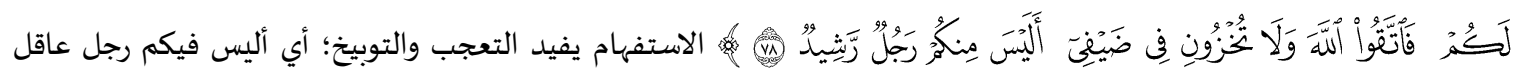

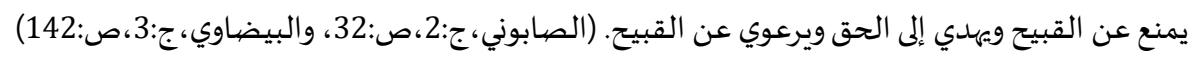
سورة يوسف: خلت من أسلوب التعجب.

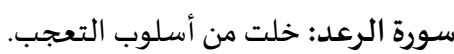

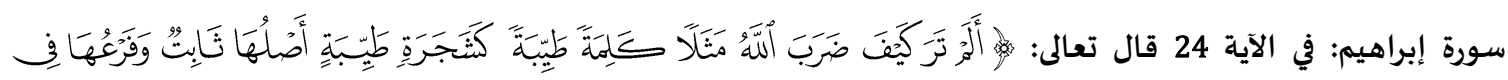

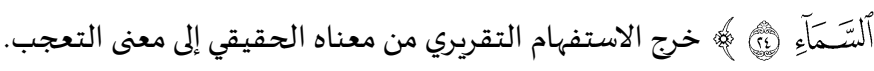

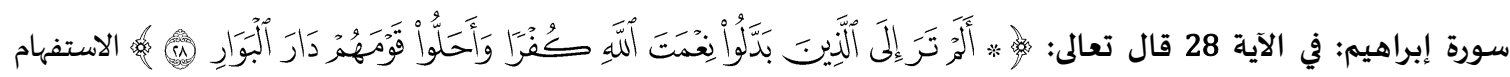

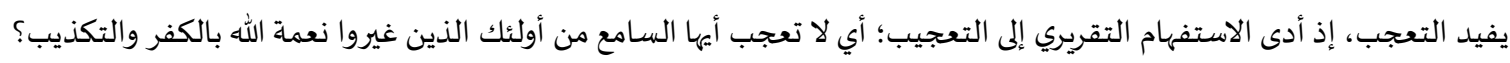

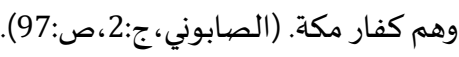

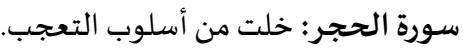




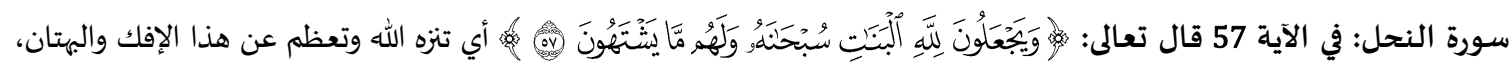

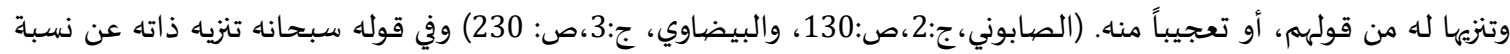

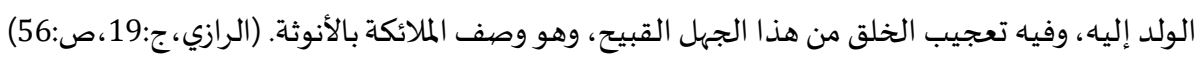
سورة الإسراء: خلت من أسلوب التعجب.

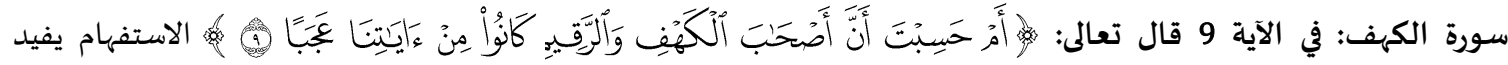

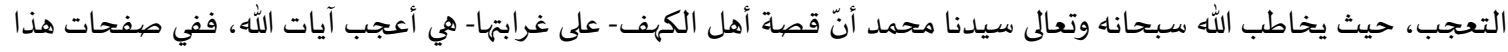

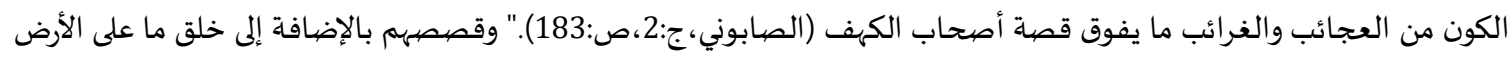

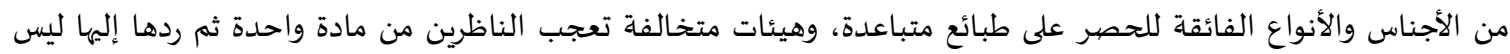

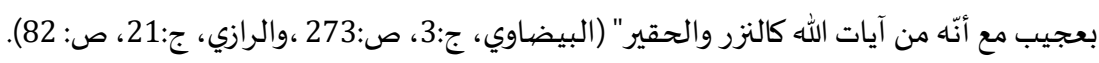

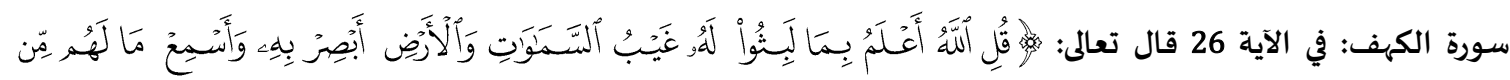

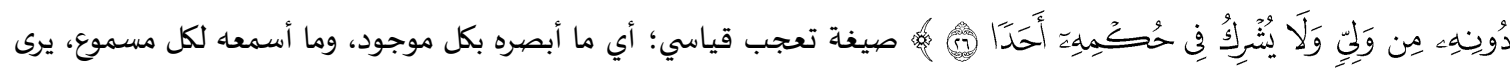

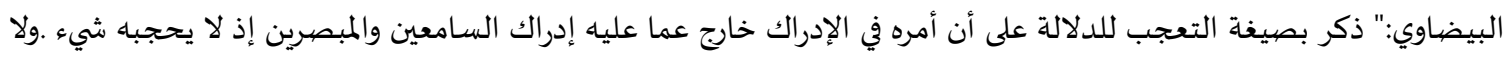

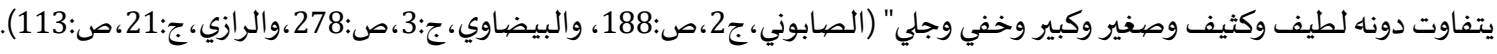

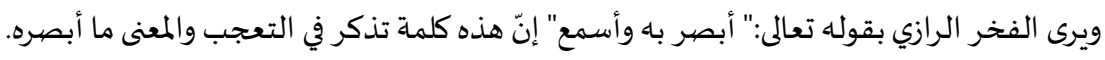

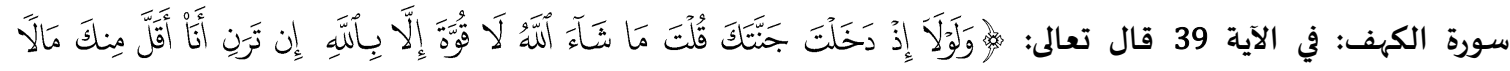

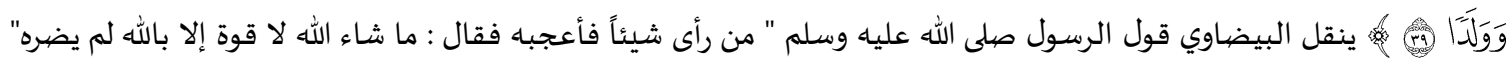

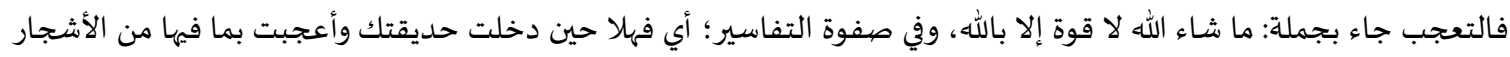

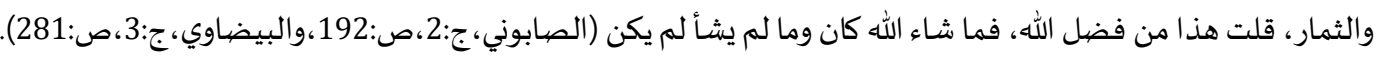

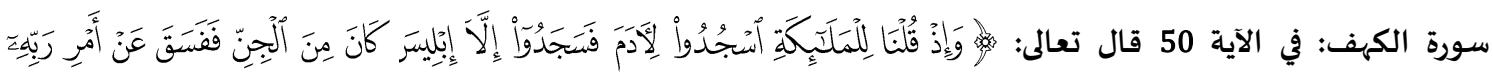

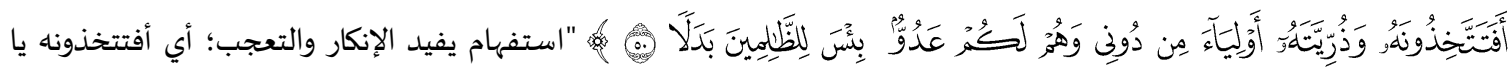

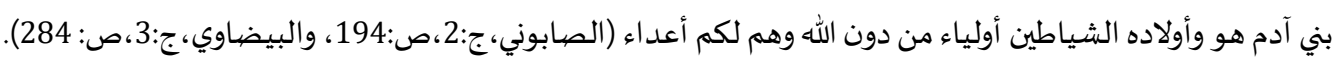

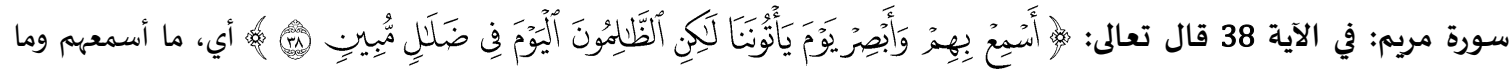

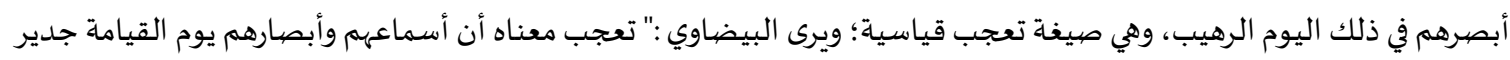

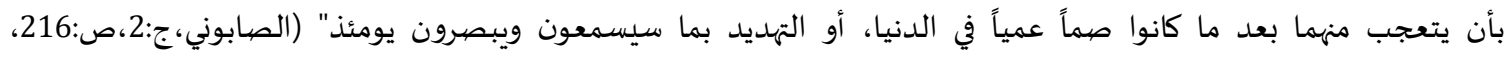
والبيضاوي، ج:4،صنص:11). سورة طه: خلت من أسلوب التعجب.

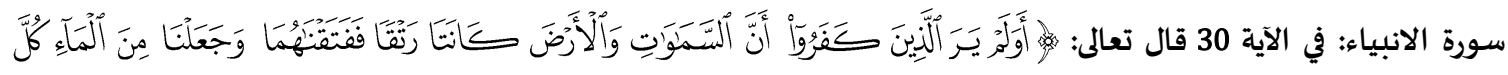

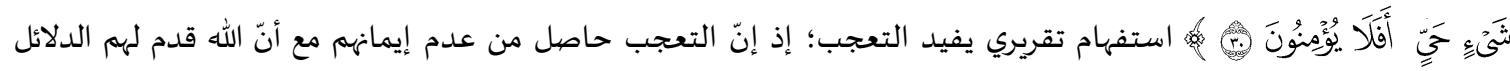

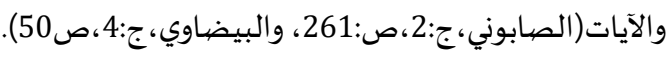

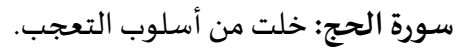
سورة المؤمنون: خلت من أسلوب التعجب. من أسبو التعب.

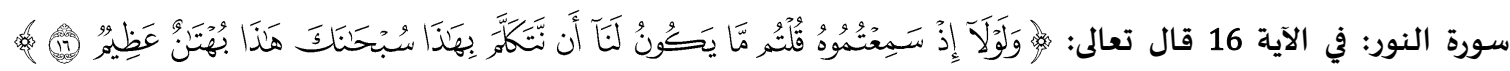

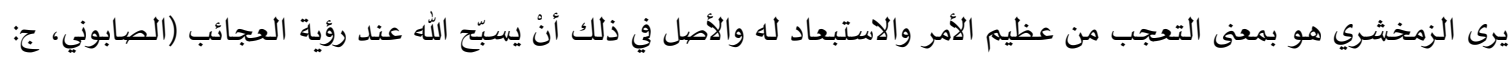

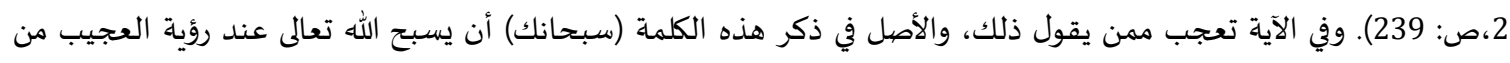

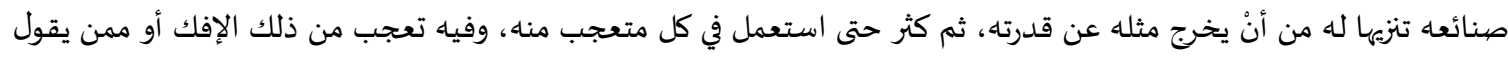

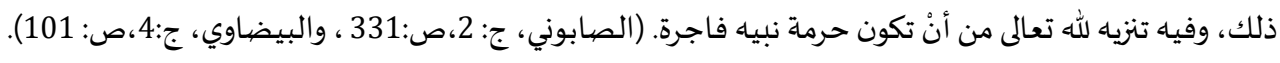




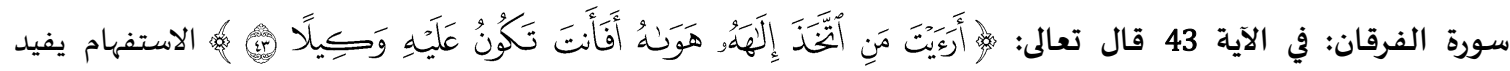

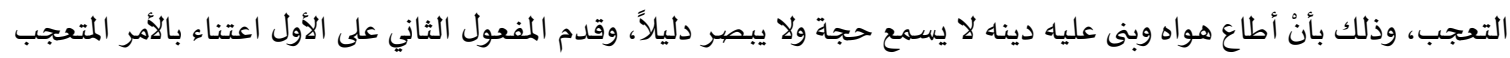

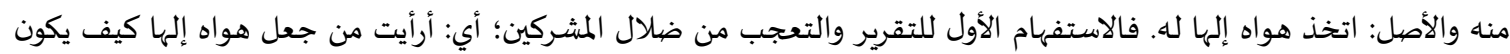

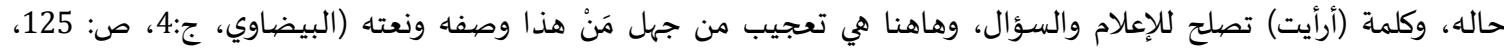

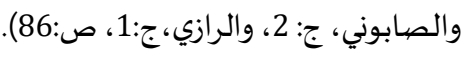

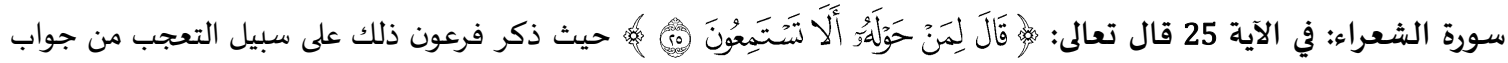

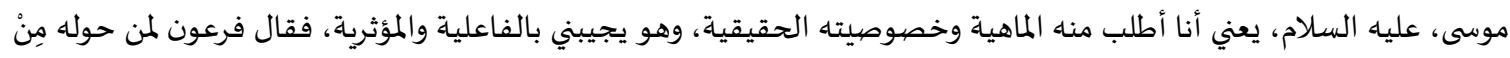
أشراف قوماه على سبيل التهمم والاستهزاء: ألا تستمعون جوابه وتعجبون من أمره؟! أسأله عن حقيقة الله فيجيبني عن صفاتهاته (الرازي،ج: 12،ص129 ، والصابوني، ج:2، ،ص:377).

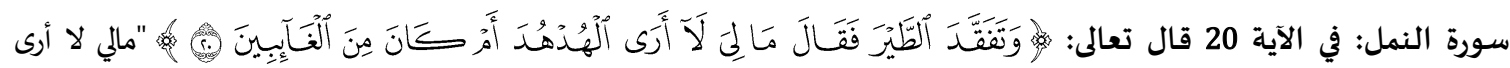

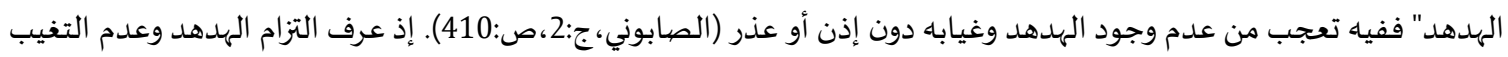

دون سبب.

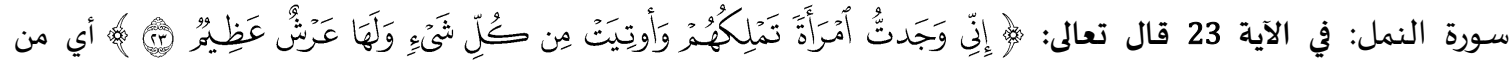

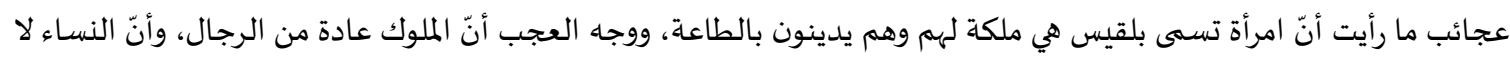

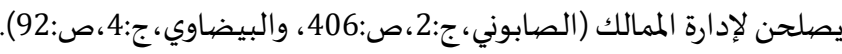

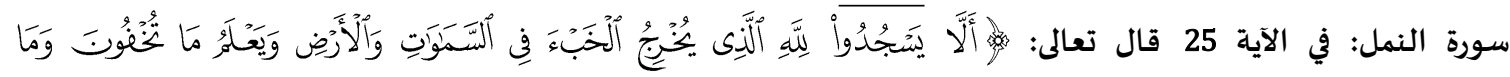

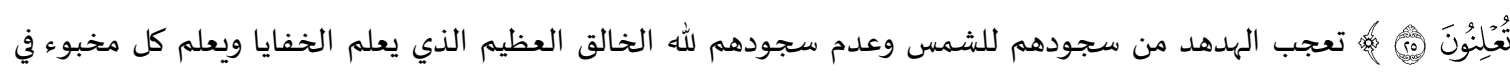

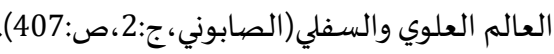

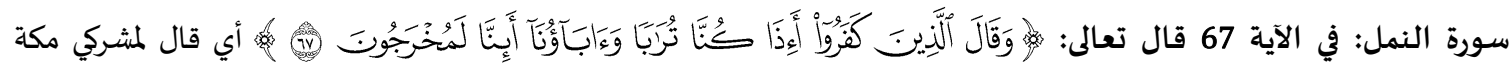

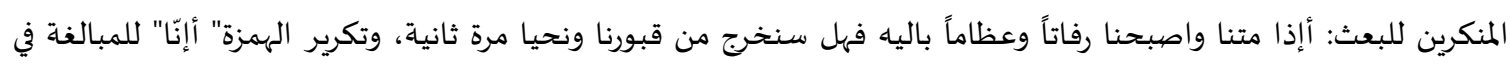

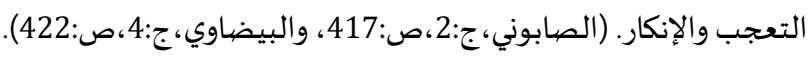

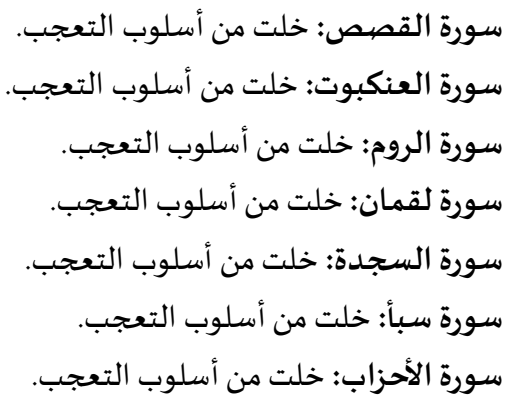

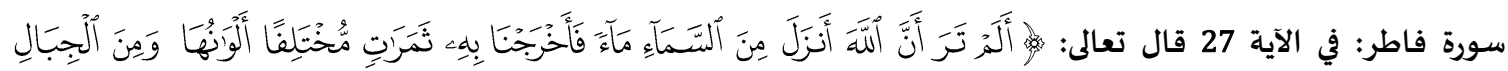

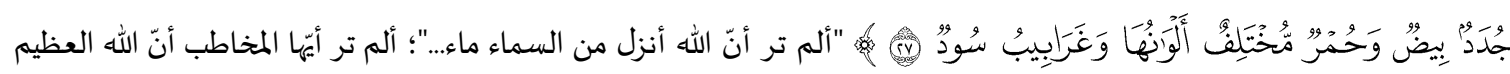

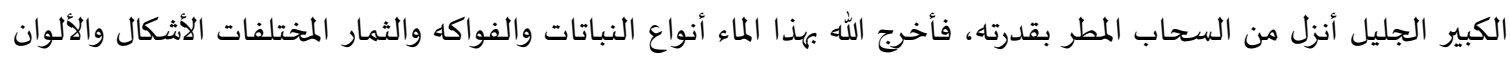

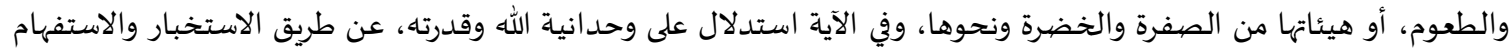

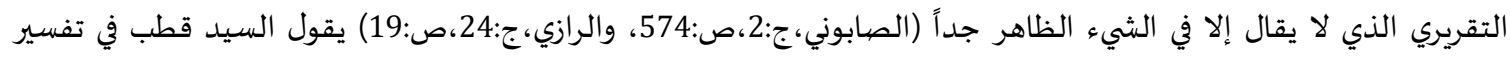

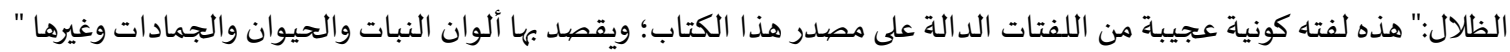

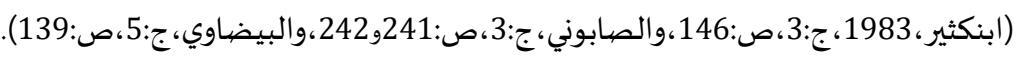
سورة يس: خلت من أسلوب التعجب.

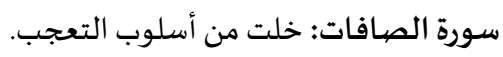




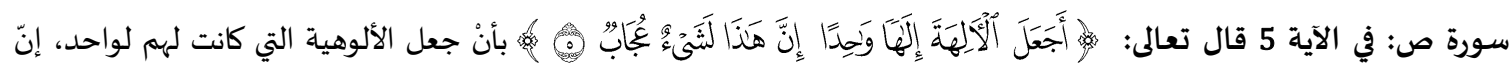

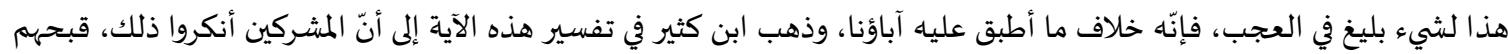

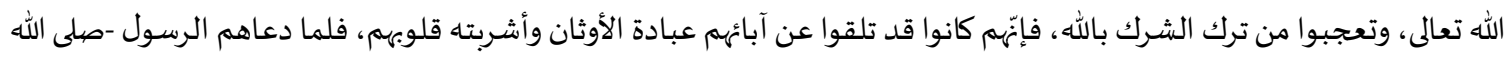

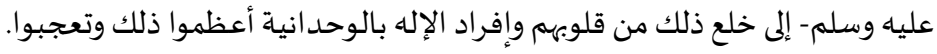

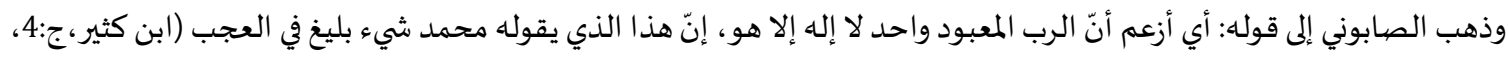

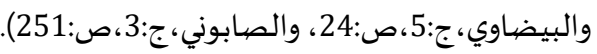

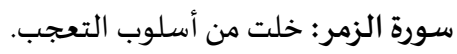

$$
\begin{aligned}
& \text { سورة غافر: خلت من أسلوب التعجب. } \\
& \text { سورة فصلت: خلت من أسلوب التعجب. } \\
& \text { سورة الشورى: خلت من أسلوب التعجب. } \\
& \text { سورة الزخرف: خلت من أسلوب التعجب. } \\
& \text { سورة الدخان: خلت من أسلوب التعجب. } \\
& \text { سورة الجاثية: خلت من أسلوب التعجب. } \\
& \text { سورة الاحقاف: خلت من أسلوب التعجب. } \\
& \text { سورة محمد: خلت من أسلوب التعجب. } \\
& \text { سورة الفتح: خلت من أسلوب التعجب. } \\
& \text { سورة الحجرات: خلت من أسلوب التعجب. }
\end{aligned}
$$

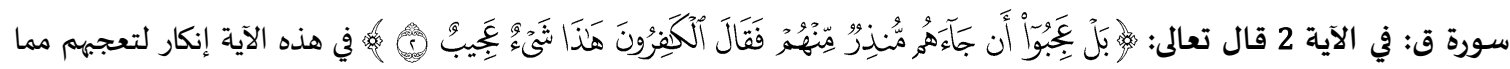

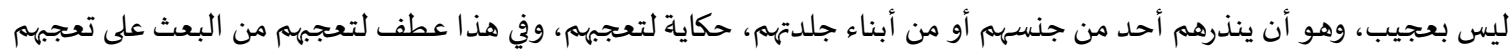

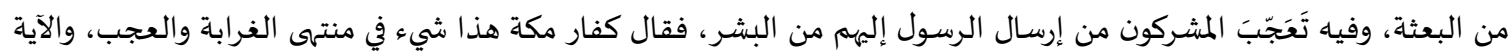

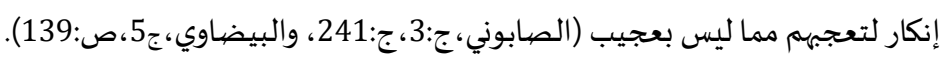

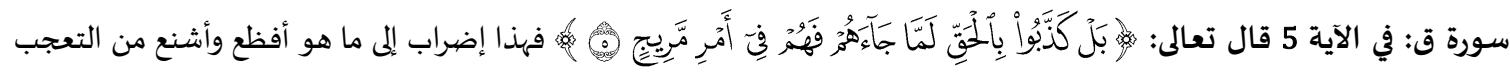

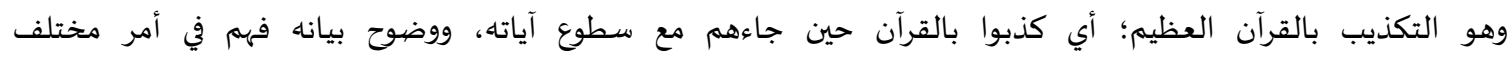

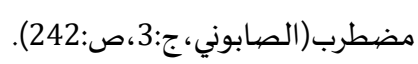

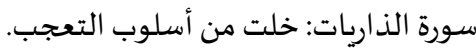

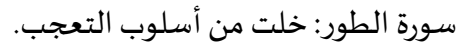
سورة النجم: خلت من أسلوب التعجب.

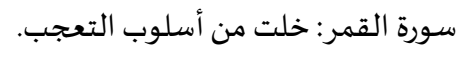

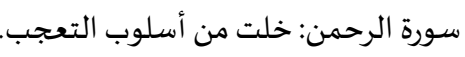
سورة الواقعة: خلت من أسلوب التعجب. شلت من أسلوب العجب.

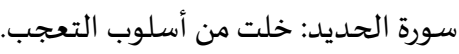

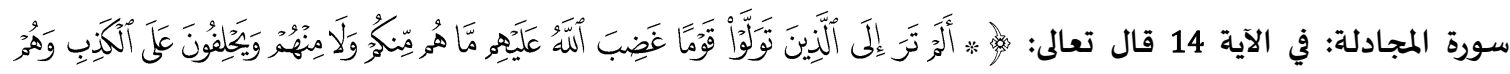

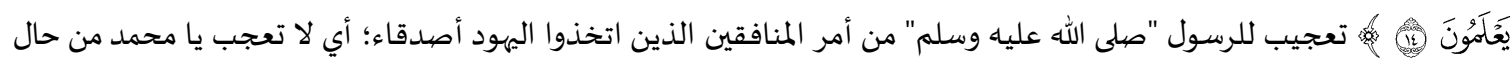
هؤلاء المنافقين الذين يزعمون الإيمان وقد اتخذوا الههود المغضوب علئه علهيهم أولياء يناصحونهم وينقلون إلهيهم أسرار المؤمنين.

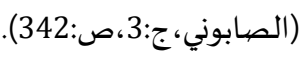

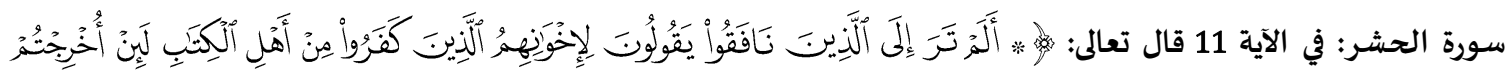

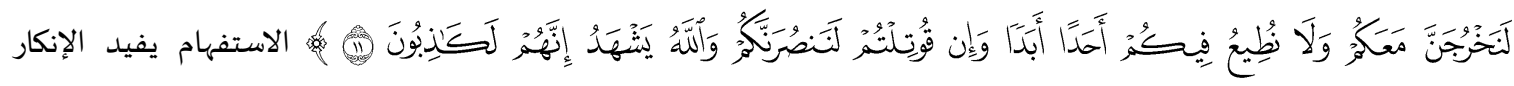


والتعجب، ففي الآية تعجيب من الله تعالى لرسوله الكريم من حال المنافقين؛ أي لا تعجب يا محمد من شأن هؤلاء المنافقين الذين

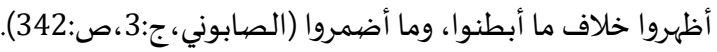

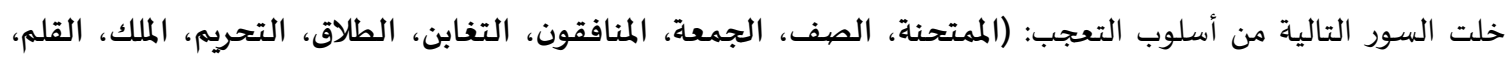
الحاقة، المعارج، نوح، الجن، المزمل، المدثر، القيامة، الإنسان، المرسلات، النبأ، النازعات).

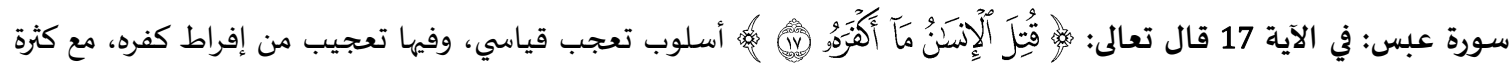

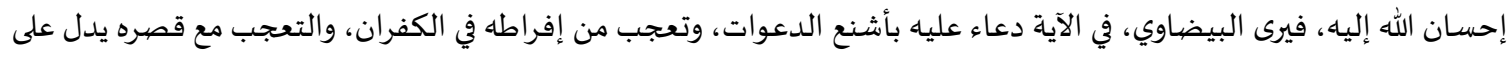

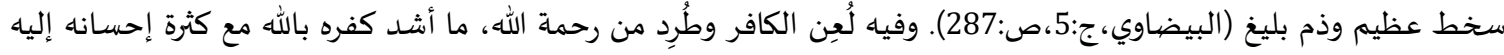

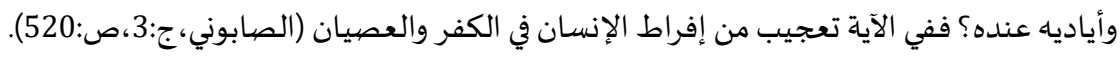

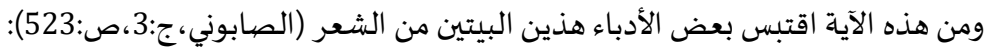

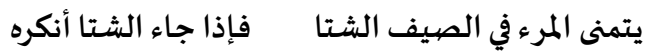

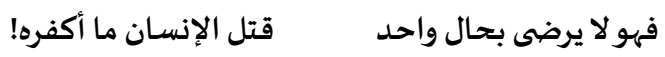

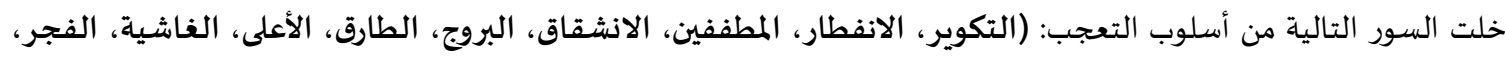
البلد، الشمس، الليل، الضشح، الشرح، التين).

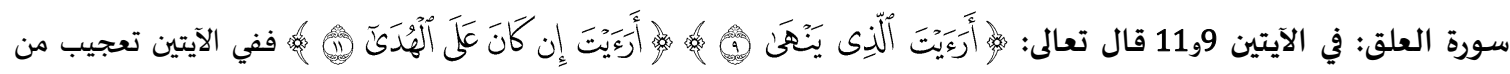

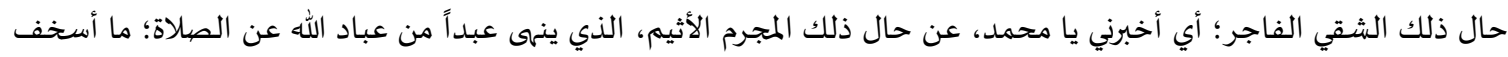

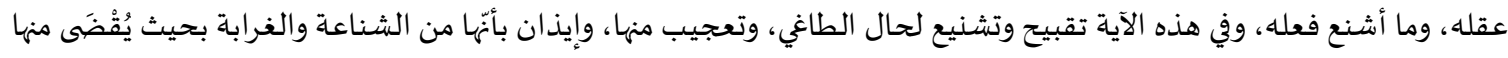

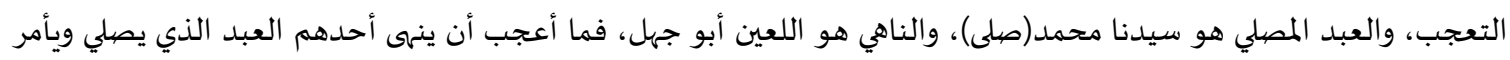

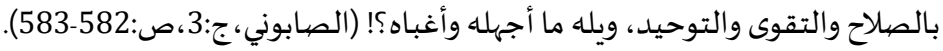
خلت سورة القدر من أسلوب التعجب.

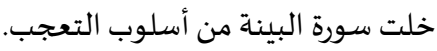

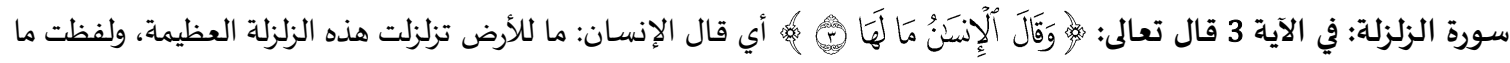

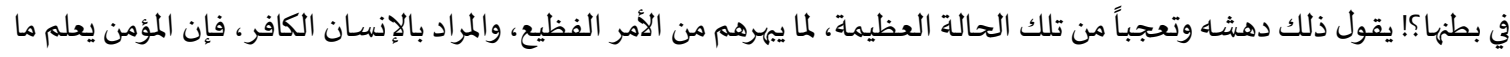

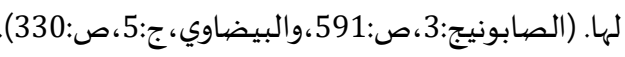
السور التالية خلت من أسلوب التعجب: (العاديات، القارعة، التكاثر، العصبر، الهمزة).

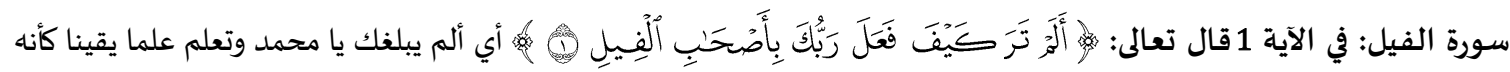

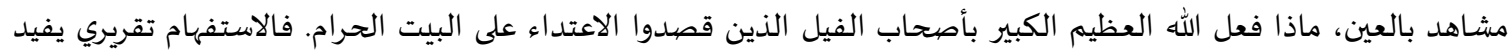

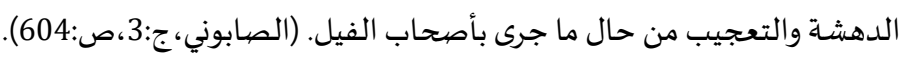
سورة قريش: خلت من أسلوب التعجب.

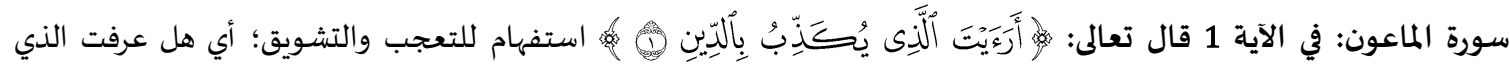

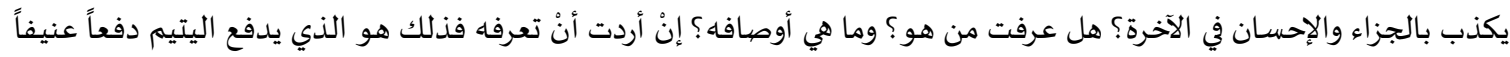

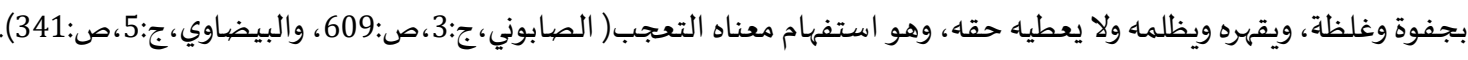

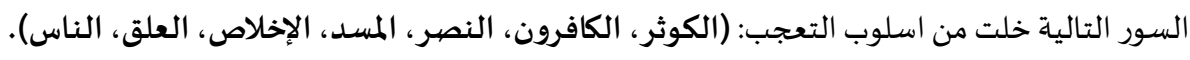

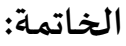
وبعد هذا التطواف في موضوع الدراسة، ودراسة كثير من مظان النحو المبوب له في الكتب القديمة والحديثة، توصلت الدراسة إلى ما يأتي: - n

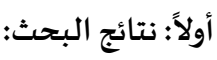
يمكن تسجيل النتائج الآتية: • ركزت الدراسات التقليدية على أسلوب التعجب القياسي بصيغتيه (ما أفعله! وأفعل به)، وأحكامه المختلفة. 
• لم تركز كتب النحو القديمة والحديثة على أسلوب التعجب السماعي، واكتفت بالتنويه إليه من خلال أمثلة قليلة وبسيطة، وكذلك من خلال الدراسات البلاغية.

أظهرت الدراسة أن استخدام أساليب التعجب السماعي في الحياة اللغوية المعاشة أكثر بكثير من أساليب التعجب القياسي. استخدم القرآن الكريم صيغتي التعجب القياسي أربع مرات فقط، في حين استخدم الأساليب الأخرى مرات عديدة تفوق الاستخدام القياسي بكثير.

أشار العلما ، في الأعم الأغلب، إلى أنه لا يجوز حصول التعجب من الله تعالى؛ ذلك لأنه يقوم على جهل المُتُعَجِبُ للسبب، وحاشا

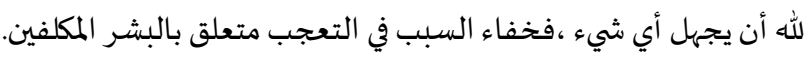
رأى اللغويون أنه لا يجوز التعجب من أسماء الله وصفاته؛ لأن التعجب يحمل في طياته شيئاً عظيماً أو غربباً أحدث التعجب، والله منزه عن ذلك.

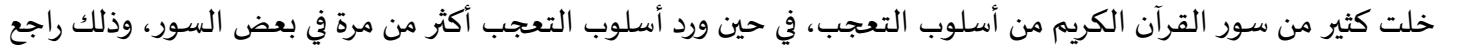

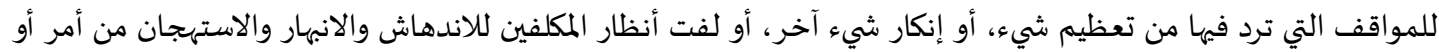
سلوك ما. القرآن الكريم معين لا ينضب في أساليبه ومعانيه، فقد ضمّ بين دفتيه الأساليب اللغوية المختلفة القياسية والسماعية، فهو

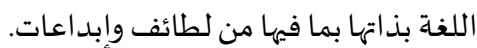
ثانياً: التوصيات: إثر هذه النتائج فإنّ الباحث يوصي بما يأتي: التأكيد على ضرورة دراسـة الأساليب القرآنية المختلفة أكثر من مرة ومن وجهات نظر مختلفة؛ لاستظهار عظمة هذا القرآن الذي يشع علماً ونوراً. التركيز في الدراسات على الجوانب التي لم يركز عليها النحويون والبلاغيون، وأخص بالذكر الجانب السماعي في اللغة صرفها ونحوها. ربط الجانب الدلالي والبلاغي في الدراسات النحوية؛ إذ لا انفكاك بين مستويات اللغة المختلفة، فاللغة كل متكامل مرتبطة العناصر لتعبر من خلالها عما يجول في خواطرنا من معان وعواطف.

المراجع:

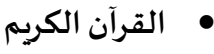

1. أحمد، أنور رحيم جبر (2017). دلالة أوجه التعجب النحوية في العربية. مجلة مركز بابل للدراسات الإنسانية: 7(1) . 2.

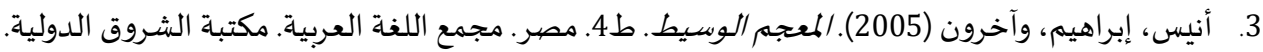

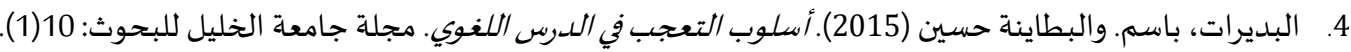
5. البيضاوي، ناصر الدين (1998). تفسير البيضاوي. ط1. إعداد وتقديم: محمد عبد الرحمن المرعشلي. بيروت. لبنان. دار إحياء التراث العربي.

6. ابن جني، أبو الفتح عثمان (2003). الخصبائص. طان. تحقيق: عبد الحميد هنداوي. لبنان. بيروت. دار الكتب العلمية.

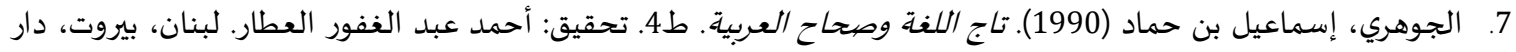
العلم للمالايين. 8. حسن، عباس (2018). النحو الوافي. ط21 ـمصر. القاهرة. دار المعارف. 9.

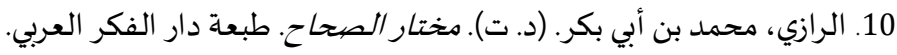

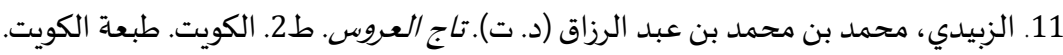

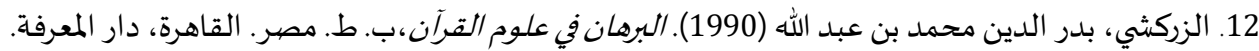


13. الزمخشري، أبو القاسم جاد الله محمود بن عمر (1998). أساس البلاغة. ط1. تحقيق: مزيد نعيم وشوقي المغربي. لبنان، بيروت، مكتبة لبنان ناشرون.

14. السامرائي، فاضل صالح (1987). معاني النحو. جامعة بغدان انداد. بيت الحكمة.

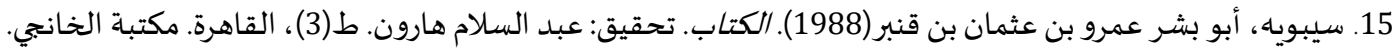

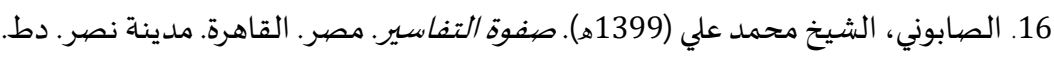

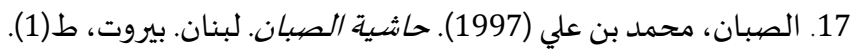

18. ابن عادل الحنبلي، أبو حفص عمر بن علي. اللباب في علوم الكتاب. تحقيق: أحمد عادل أحمد عبد الموجود. وآخرون، لبنان،

$$
\text { بيروت. دار الكتب العلمية. }
$$

19. عبد الجاسم، عبد العباس (2016). الصواب في معرفة القواعد والإعراب. ط:1 الأردن، عمان. دار دجلة.

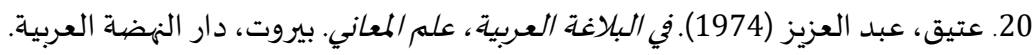

21. أبو العروس، يوسف (2007). مدخل إلى البلاغة العربية ط(1). عمان، دار المسيرة للنشر والتوزيع والطباعة.

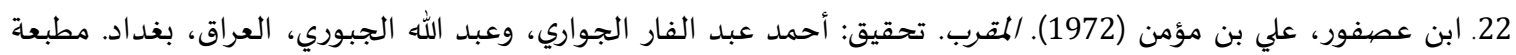

$$
\text { العاني، ط(1). (1). }
$$

23. ابن عطية، أبو محمد عبد الحق بن غالب الأندلسي. المحرر الوجيز في تفسير الكتاب العزيز. لبنان. بيروت، دار الكتب العلمية.

24. ابن فارس، أحمد (1979). معجم مقاييس اللغة. تحقيق: عبد السلام هارون ط(25). لبنان، بيروت، دار الفكر للطباعة والنشر.

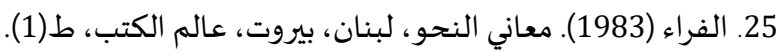

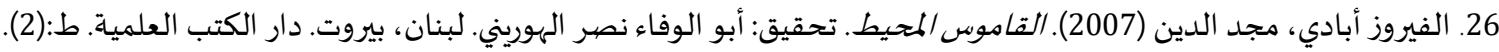

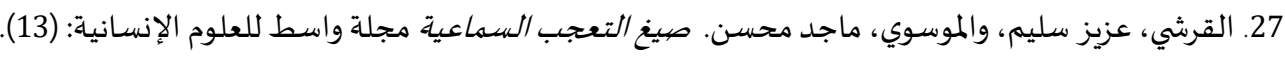

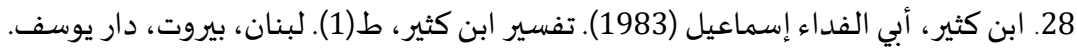

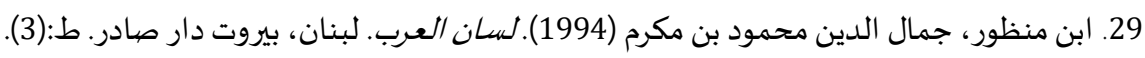

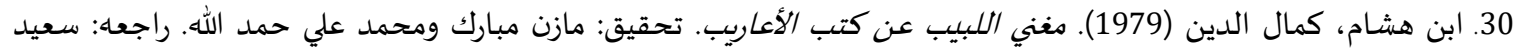

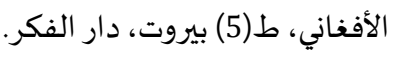

31. ابن يعيش (2001). شرح المفضل، تقديم إيميل بديع يعقوب، لبنان، بيروت، دار الكتب العلمية. ط(1). 
International Journal for Arabic Linguistics and Literature Studies (JALLS)

\title{
The style of exclamation in the Holy Quran
}

\author{
Jamal N. Rabah \\ Assistant Professor, Al-Quds Open University, Palestine \\ jnibraheem@qou.edu
}

Received : 29/5/2021 Revised : 28/6/2021 Accepted : 10/7/2021 DOI : https://doi.org/10.31559/JALLS2021.3.2.4

\begin{abstract}
The aim of this study is to reveal the metaphorical and standard exclamation method in the Holy Quran, and the role of the exclamation method in highlighting intended meanings and their reflections on the respondent. The study has tackled a crucial topic and that is the range of utilizing the exclamation method in the Holy Quran in its standard pattern as presented in grammar books and the metaphorical pattern which has not been emphasized neither by grammatical studies nor books.

The study has proved that the major usage of the exclamation in the Holy Quran was in the metaphorical method in all its forms particularly in ratification which includes metaphorical meanings including exclamation in which exclamation has been fully used in its different pronunciation patterns including (ajab, ajeeb and ojab) عجب, عجيب, عجاب, in addition to many other expressions. On the other hand, other exclamation expressions including (ma afealh and afeal bih) ما افعله! و أفعل به! have been rarely used the thing which emphasizes the importance of the metaphorical methods.

This research is broken into two chapters; an introduction, preface and a conclusion. Chapter one emphasized the concept of the "exclamation" in Arabic language, in addition to standardized and metaphorical exclamations methods in different grammar books. Chapter two researched the exclamation method in its two forms in the Holy Quran, the effect of its usage in the clarification of the meanings and their effect on the respondent with the help of language and interpretation references. The study came up with a conclusion which includes the findings and recommendations of the research which are based on the descriptive approach for its suitability of this kind of research.
\end{abstract}

\section{Keywords: metaphorical exclamation; standard exclamation; Holy Quran.}

\section{References:}

1. Abn 'adl Alhnbly, Abw Hfs 'mr Bn 'ly. Allbab Fy 'lwm Alktab. Thqyq: Ahmd 'adl Ahmd 'bd Almwjwd. Wakhrwn, Lbnan, Byrwt. Dar Alktb Al'lmyh.

2. 'bd Aljasm, 'bd Al'bas (2016). Alswab Fy M'rft Alqwa'd Wale'rab. T:1 Alardn, 'man. Dar Djlh.

3. Abw Al'rws, Ywsf (2007). Mdkhl Ela Alblaghh Al'rbyh T(1). 'man, Dar Almsyrh Llnshr Waltwzy' Waltba'h.

4. Abn 'sfwr, 'ly Bn M'mn (1972). Almqrb. Thqyq: Ahmd 'bd Alfar Aljwary, W'bd Allh Aljbwry, Al'raq, Bghdad. Mtb't Al'any, T(1).

5. 'tyq, 'bd Al'zyz (1974). Fy Alblaghh Al'rbyh, 'Im Alm'any. Byrwt, Dar Alnhdh Al'rbyh.

6. Abn 'tyh, Abw Mhmd 'bd Alhq Bn Ghalb Alandlsy. Almhrr Alwjyz Fy Tfsyr Alktab Al'zyz. Lbnan. Byrwt, Dar Alktb Al'Imyh. T(1).

7. Ahmd, Anwr Rhym Jbr(2017). Dlalh Awjh Alt'ejb Alnhwyh Fy Al'rbyh. Mjlt Mrkz Babl Lldrasat Alensanyh: $7(1)$.

8. Anys, Ebrahym, Wakhrwn (2005). Alm'jm Alwsyt. T4. Msr. Mjm' Allghh Al'rbyh. Mktbt Alshrwq Aldwlyh. 
9. Alastrbady, Rdy Aldyn (1978). Shrh Alrdy 'la Alkafyh.B.T. T'lyq: Ywsf Hsn 'mr. Mnshwrat Jam't Qad Ywns.

10. Albdyrat, Basm. Walbtaynh Hsyn (2015). Aslwb Alt'jb Fy Aldrs Allghwy. Mjlt Jam't Alkhlyl Llbhwth: 10(1).

11. Albydawy, Nasr Aldyn (1998). Tfsyr Albydawy. T1. E'dad Wtqdym: Mhmd 'bd Alrhmn Almr'shly. Byrwt. Lbnan. Dar Ehya' Altrath Al'rby.

12. Dlwm, Mhmd. Virtues Campus.univ-msila.dz/f//wp-content/up10ads/2016/11/alt'ejbpdf

13. Abn Fars, Ahmd (1979). M'jm Mqayys Allghh. Thqyq: 'bd Alslam Harwn T(2). Lbnan, Byrwt, Dar Alfkr Lltba'h Walnshr.

14. Alfra' (1983). M'any Alnhw, Lbnan, Byrwt, 'alm Alktb, T(1).

15. Alfyrwz Abady, Mjd Aldyn (2007). Alqamws Almhyt. Thqyq: Abw Alwfa' Nsr Alhwryny. Lbnan, Byrwt. Dar Alktb Al'lmyh. T:(2).

16. Abn Hsham, Kmal Aldyn (1979). Mghny Allbyb 'n Ktb Ala'aryb. Thqyq: Mazn Mbark Wmhmd 'ly Hmd Allh. Raj'h: S'yd Alafghany, T(5) Byrwt, Dar Alfkr.

17. Hsn, 'bas (2018). Alnhw Alwafy. T21.Msr. Alqahrh. Dar Alm'arf.

18. Abn Jny, Abw Alfth 'Ethman (2003). Alkhsa's. T2. Thqyq: 'bd Alhmyd Hndawy. Lbnan. Byrwt. Dar Alktb Al'lmyh.

19. Aljwhry, Esma'yl Bn Hmad (1990). Taj Allghh Wshat Al'rbyh. T4. Thqyq: Ahmd 'bd Alghfwr Al'tar. Lbnan, Byrwt, Dar Al'Im Llmlayyn.

20. Abn Kthyr, Aby Alfda' Esma'yl (1983). Tfsyr Abn Kthyr, T(1). Lbnan, Byrwt, Dar Ywsf.

21. Abn Mnzwr, Jmal Aldyn Mhmwd Bn Mkrm (1994). Lsan Al'rb. Lbnan, Byrwt Dar Sadr. T:(3).

22. Alqrshy, 'zyz Slym, Walmwswy, Majd Mhsn. Sygh Alt'jb Alsma'yh Mjlh Wast Ll'lwm Alensanyh: (13).

23. Alrazy, Mhmd Bn Aby Bkr. (D. T). Mkhtar Alshah. Tb't Dar Alfkr Al'rby.

24. Alsban, Mhmd Bn 'ly (1997). Hashyt Alsban. Lbnan. Byrwt, T (1).

25. Alsabwny, Alshykh Mhmd 'ly (1399h). Sfwt Altfasyr. Msr. Alqahrh. Mdynh Nsr. Dt.

26. Alsamra'y, Fadl Salh (1987). M'any Alnhw. Jam't Bghdad. Byt Alhkmh.

27. Sybwyh, Abw Bshr 'mrw Bn 'thman Bn Qnbr (1988). Alktab. Thqyq: 'bd Alslam Harwn. T(3), Alqahrh. Mktbt Alkhanjy.

28. Abn Y'ysh (2001). Shrh Almfdl, Tqdym Eymyl Bdy' Y'qwb, Lbnan, Byrwt, Dar Alktb Al'Imyh. T(1).

29. Alzbydy, Mhmd Bn Mhmd Bn 'bd Alrzaq (D. T). Taj Al'rws. T2. Alkwyt. Tb't Alkwyt.

30. Alzmkhshry, Abw Alqasm Jad Allh Mhmwd Bn 'mr (1998). Asas Alblaghh. T1. Thqyq: Mzyd N'ym Wshwqy Almghrby. Lbnan, Byrwt, Mktbt Lbnan Nashrwn.

31. Alzrkshy, Bdr Aldyn Mhmd Bn 'bd Allh (1990). Albrhan Fy 'lwm Alqran,B. T. Msr. Alqahrh, Dar Alm'rfh. 